\title{
La segregación socioespacial en Culiacán, México (2000-2010): ¿de la ciudad dual a la ciudad fragmentada?
}

\section{Socio-spatial segregation in Culiacan, Mexico (2000-2010): From dual city to fragmented city?}

\author{
B. Nayeli Pérez-Tamayo* \\ Fernando Gil-Alonso** \\ Jordi Bayona-i-Carrasco***
}

\section{Resumen}

Con el fin de contribuir al entendimiento de los procesos de segregación socioespacial de las ciudades medias mexicanas, este trabajo analiza la distribución espacial de la población de Culiacán, México, empleando distintas características sociodemográficas que dan cuenta de la manera en que se vive la segregación socioespacial en el territorio, así como su evolución entre los años 2000 y 2010. Los resultados indican la existencia de rasgos segregativos que coinciden con el modelo tradicional latinoamericano, visualizados en la ubicación central de los grupos sociales más privilegiados y en la dispersión de los estratos más bajos hacia las periferias. A su vez, se presentan procesos novedosos que apuntan a un cambio desde el tradicional patrón de segregación centro-periferia hacia el nuevo modelo de la ciudad fragmen-

* Becaria doctoral Conacyt-México, para el programa de Doctorado en Geografía, Planificación Territorial y Gestión Ambiental, Universidad de Barcelona, Facultad de Geografía e Historia, Departamento de Geografía. Dirección postal: Montalegre 6, C.P. 08001, Barcelona, España. Correo electrónico: nayept@gmail.com

** Departamento de Geografía, Universidad de Barcelona. Dirección postal: Montalegre 6, C.P. 08001, Barcelona, España. Correo electrónico: fgil@ub.edu

*** Centre d'Estudis Demogràfics / CERCA y Departamento de Geografía, Universidad de Barcelona. Dirección postal: Montalegre 6, C.P. 08001, Barcelona, España. Correo electrónico: jordibayona@ub.edu

Nota de los autores: Agradecemos al Consejo Nacional de Ciencia y Tecnología por la beca doctoral que hizo posible esta investigación, así como al programa Doctores Jóvenes de la Universidad Autónoma de Sinaloa. Este trabajo se realizó en el marco del proyecto de I+D+i "Desigualdad social, polarización territorial y formación de espacios vulnerables en las grandes áreas metropolitanas españolas" (CSO2015-65219-C2-1-R), dirigido por la doctora Isabel Pujadas y el doctor Fernando Gil Alonso, y financiado por la Agencia Estatal de Investigación (AEI) y por el Fondo Europeo de Desarrollo Regional (FEDER, UE). Los autores pertenecen al grupo de investigación Territori, Població i Ciutadania (Ref. 2014SGR380), financiado por la Generalitat de Catalunya y coordinado por la doctora Pujadas. 
tada, destacándose la apertura de alternativas residenciales para las élites fuera de los espacios centrales, aunque con desarrollos de tipo cerrado y contiguos a asentamientos de bajos ingresos.

Palabras clave: segregación espacial; desigualdad social; fragmentación; ciudades medias; estudio de caso; México.

\begin{abstract}
This paper analyzes the spatial distribution of the population of Culiacán, Mexico, using various sociodemographic features that explain the way socio-spatial segregation is experienced, in order to contribute to an understanding of the socio-spatial segregation processes of medium-sized cities throughout the country as well as their evolution between 2000 and 2010. The results indicate the existence of segregative features that coincide with the traditional Latin American model, visualized in the central location of the most privileged social groups and the banishment of the lowest strata to the peripheries. At the same time, new processes are presented that point to a shift from the traditional center-periphery segregation pattern to the new model of the fragmented city, highlighting the creation of residential alternatives for the elites outside central spaces, with gated communities adjoining low income settlements.
\end{abstract}

Keywords: spatial segregation; social inequality; fragmentation; mediumsized cities; case study; Mexico.

\title{
1. Introducción
}

Entre los problemas que condicionan el desarrollo de las ciudades latinoamericanas contemporáneas, dos son quizás los más importantes: la dinámica de crecimiento explosivo, tanto en términos demográficos como espaciales, y el incremento de la desigualdad social. Esto último da lugar a la exclusión social de una parte de su población, así como a procesos de segregación en todas sus expresiones. En sentido estricto, la segregación se puede definir como las "formas de desigual distribución de grupos de población en el territorio" (Rodríguez y Arriagada, 2004: 6; White, 1983), grupos que pueden estar conformados por individuos que comparten ciertas características, como una misma condición social, religiosa, étnica, cultural, profesional o etaria. Se puede estudiar la segregación desde múltiples acepciones y disciplinas (aunque en este artículo se primarán los enfoques sociológico y geográfico), teniendo todas ellas en común el interés por analizar el aislamiento espacial de un grupo de personas respecto de otro distinto; dicho aislamiento también puede traducirse en términos de concentración.

La segregación en sí misma no tiene por qué ser negativa (Peach, 1996), pues existe una tendencia natural a la agrupación de los individuos. Sin 
embargo, cuando se ve acompañada por la creación de barreras territoriales y simbólicas que dificultan la integración de un grupo en la sociedad, e introducen además esquemas de distinción y estigmatización, entonces sí que se convierte en un problema, sobre todo para quienes presentan las condiciones de vida más desfavorables y precarias, lo que alimenta el círculo de aislamiento y exclusión social que predomina en la segregación. Por ello es particularmente interesante el análisis de este fenómeno según la condición social de los individuos (que algunos investigadores, más allá de las características sociodemográficas de los mismos, determinan a partir de las diferencias en el acceso y características de sus viviendas, mientras que otros la analizan en función de los bienes de consumo que poseen) porque la segregación así definida se traduce en la desigualdad de las condiciones de acceso a los beneficios de la ciudad en función de la zona donde se habita. Es entonces la segregación residencial socioeconómica, o separación espacial de los individuos con distintas características socioeconómicas, la que se aborda en este trabajo.

En América Latina, y a pesar del reconocimiento de la importancia de este fenómeno desde décadas atrás, no ha sido sino hasta fechas recientes que se ha profundizado en el estudio empírico de los procesos urbanos de segregación socioespacial, debido a la escasez de datos y la dificultad de acceder a la información necesaria (Monkkonen, 2012). Entender la segregación de las ciudades de este territorio es de suma importancia, puesto que en Latinoamérica se observan las desigualdades socioeconómicas y por ingreso más altas del mundo, con marcadas divisiones de clase. En México, particularmente, los estudios se han enfocado tradicionalmente a grandes ciudades y áreas metropolitanas (CEPAL, 2012 y 2014). Por el contrario, las ciudades de tamaño medio han sido escasamente estudiadas en cuanto al fenómeno segregativo, salvo recientes y crecientes excepciones (González, 2005; Ariza y Solís, 2009; Acosta, 2015; Domínguez, 2017), a pesar de que actualmente son las que más crecen. Para Sabatini representan el futuro de la región y "el aprendizaje que se logre en las ciudades intermedias podría, incluso, ayudar a mejorar la gestión urbana y la situación de las ciudades de mayor tamaño" (Sabatini, 1998: 129). Por ello creemos que esta investigación focalizada en Culiacán, tomada como ejemplo de ciudad media mexicana, y para la que apenas existen análisis al respecto, representa un aporte empírico significativo.

El objetivo de este trabajo es analizar el nivel y el patrón de la segregación residencial socioeconómica de Culiacán y su evolución entre los años 2000 y 2010. Para ello se partirá de la hipótesis -que se desarrolla en el apartado 2- de que Culiacán es un buen ejemplo de la transición desde el patrón 
tradicional de segregación residencial de las ciudades latinoamericanas (el denominado modelo centro-periferia) hacia el patrón de ciudad "fragmentada", caracterizado por la diversificación social de la periferia, en la que se encuentran tanto "villas miseria" -fruto de la ocupación irregular del suelo y barrios obreros de promoción pública o privada-, como colonias de clase media y alta a menudo en forma de "fraccionamientos cerrados" (Borsdorf, 2003). Validar esta hipótesis mediante una descripción de la evolución de las pautas de localización de las clases sociales o estratos socioeconómicos de Culiacán, con la cartografía de una serie de indicadores cuantitativos, será uno de los objetivos específicos de este trabajo. El otro será medir el aumento o disminución de los niveles de segregación a partir del uso de indicadores, que se explican en el apartado 3, donde también se discute sobre el alcance y limitaciones de éstos. El capítulo 4 presenta a Culiacán y su área urbana, mientras que en el 5, que es el principal, se presentan los resultados, que finalmente se discuten y resumen en las conclusiones.

\section{Antecedentes sobre el estudio de la segregación}

La pobreza y la exclusión social son fenómenos que tienden a concentrarse en las urbes y que suelen estar asociados a procesos segregativos. Resulta evidente que, ya desde la época preindustrial (Nightingale, 2012), las ciudades se segmentan en sectores según las características socioeconómicas de sus habitantes, en ocasiones muy claramente diferenciados, mientras que en otros casos se puede tratar de una especie de mixtura que logra minimizar los contrastes existentes entre ellos. La segregación residencial socioeconómica es, por lo tanto, una de las expresiones más evidentes de dicha segmentación social, dando lugar a implicaciones predominantemente negativas frente a las positivas -como la preservación de costumbres e identidades de grupos minoritarios, o la creación de negocios étnicos-, de tal manera que cada vez son más los estigmas asociados a estas áreas, como la desintegración familiar, el aumento de la economía informal y la acentuación de la delincuencia (Kessler y Di Virgilio, 2008; Sabatini, 2003b).

Así pues, conocer la localización espacial de los distintos grupos sociales bajo los cuales se configura el territorio, como parte de la comprensión del fenómeno segregativo, tiene implicaciones importantes para las relaciones sociales y la gobernabilidad de las áreas urbanas. Pero incluso más importante es entender las causas sobre las que reposa este fenómeno, pues su identificación permitirá hacer frente a su propagación, ya que la segregación residencial actúa como reproductor de las desigualdades socioeconómicas (Rodríguez 
y Arriagada, 2004). Ello es particularmente cierto en Latinoamérica, dados los enormes niveles de desigualdad existentes (Roberts y Wilson, 2009).

\subsection{El concepto de segregación y sus causas}

El estudio de la segregación como fenómeno fundamentalmente característico de las ciudades aparece por primera vez en la esfera internacional hacia inicios del siglo XX, cuando aparecen en Estados Unidos los primeros análisis que presentan el fenómeno explícito de la segregación socioespacial. Se trata de las investigaciones realizadas en el Departamento de Sociología de la Escuela de Chicago (donde destacan Robert E. Park, Ernest W. Burgess y Louis Wirth; véase Martínez, 1999) y que parten del concepto de "ecología humana" para tratar de explicar los "problemas" de la ciudad a partir de una visión orgánica de ésta, haciendo una analogía y comparándolos con los procesos y fenómenos biológicos presentes en la naturaleza. Desde esta perspectiva, se explicó la concentración de los grupos sociales de bajos ingresos y de los grupos étnicos más desfavorecidos en las zonas centrales de la ciudad como consecuencia de cierto "darwinismo social". Desde estos inicios, la diferenciación de la localización de los inmigrantes en el espacio urbano fue uno de los temas más analizados en Estados Unidos, refinándose progresivamente los métodos de cuantificación del fenómeno con la creación de índices de segregación (Duncan y Duncan, 1955), y las metodologías social areas analysis, spatial analysis y factorial ecology.

A mediados de los años sesenta las percepciones y preferencias residenciales de los individuos, incluyendo condicionantes de tipo étnico, cultural y religioso, fueron introducidas en las teorías explicativas como inductores (únicos o preferentes) de la diferenciación espacial (behavioural approach, ethnic-cultural approach, recogidos en Bayona, 2006). Esta línea de investigación no considera que la segregación residencial sea esencialmente el producto de una segregación económica, sino que prioriza los deseos de los individuos de agruparse con otros con sus mismas características. Se cree así que existen "umbrales de tolerancia individual" en relación con las características de los vecinos inmediatos, poniéndose como ejemplo las preferencias raciales de un individuo: una vez superado el límite o umbral, se desencadena un cambio residencial hacia otra área que se adapte mejor a sus preferencias, creándose así un efecto bola de nieve de cambios residenciales en cadena que acaban alterando la composición de la zona (Schelling, 1978).

Paralelamente, otra línea de investigación de carácter marxista atribuye la causa principal de la segregación a los efectos del sistema de acumulación 
capitalista, que origina intensas desigualdades económicas y sociales, así como una constante lucha de clases que se transfiere al territorio, situando así a los individuos en éste según su condición económica o posibilidad de acumular capital. Desde esta perspectiva se deduce que la segregación es producto de las fuerzas del mercado, de la interacción entre la estructura social y la segmentación del mercado residencial, que a su vez se traduce en la fragmentación de las clases sociales que se ve reflejada sobre el territorio y el entorno habitacional de dichas clases. Así pues, las hipótesis anteriores, que tratan de explicar el origen de la segregación desde la óptica de la ecología humana y desde las preferencias y percepciones individuales, son refutadas argumentando que dichas preferencias se encuentran sometidas al funcionamiento del mercado y a la posición que el individuo tenga dentro del sistema, que acaba determinando los patrones de ubicación residencial. Ello sería así porque las redes de relaciones sociales se establecen a partir de la posición social del individuo, factor que influye en gran medida en la creación de mapas mentales urbanos y que acaba por establecer el uso de la ciudad y las preferencias residenciales de los individuos.

Las investigaciones más recientes apuntan hacia una coexistencia y complementación de todas estas teorías, asumiendo que, en general, las causas que inducen hacia un crecimiento de la segregación socioespacial son complejas y con diversos matices (Fossett, 2006; Ibraimovic y Masiero, 2014). Así, la discusión actual sobre la segregación en Estados Unidos y otros países desarrollados se centra en temas como la persistencia del guetto en ciertas "minorías" étnicas (Charles, 2003) y sus efectos nocivos y reproductores de la desigualdad y segregación, lo que se conoce como "efecto barrio" (van Ham, 2012; Sampson, 2012); el debate sobre si las políticas públicas se deben enfocar en combatir la segregación económica (Wilson, 1987; Jargowsky, 1997) o la segregación racial (Massey y Denton, 1993; Wacquant, 1997); y la suburbanización de las clases media y alta -y la incorporación de las minorías a dicho movimiento- y el deterioro de barrios obreros tradicionales en paralelo a la gentrificación de zonas céntricas previamente deterioradas. Además, se asume que la segregación es un fenómeno marcadamente contextual, con una fuerte incidencia de las circunstancias locales para interpretar su evolución (Porcel, 2016).

Sólo algunos de estos debates son pertinentes para América Latina, donde se ha dado más importancia al estudio de la segregación urbana por causas socioeconómicas o clases sociales que a la determinada por diferencias étnicas o raciales, o por comunidades de inmigrantes, más frecuente en Estados Unidos y Europa. 


\subsection{Patrones de segregación y manifestaciones predominantes en América Latina}

Para el caso latinoamericano, fue durante las décadas de los sesenta y setenta cuando aparecieron un buen número de investigaciones que abordan la problemática de las clases sociales y su estratificación social (Schteingart, 2001), aunque inicialmente con poco interés en el estudio de su segmentación en el territorio, al menos en el caso mexicano, donde desde el principio las investigaciones se centraron en las grandes ciudades.

Cuando en décadas recientes se han desarrollado en México y en el resto de América Latina investigaciones sobre la segregación residencial, el debate se ha centrado, como se ha indicado, principalmente en los aspectos socioeconómicos, y con distintos matices con respecto a lo experimentado en otros contextos, como el europeo y estadounidense. Estas particularidades que condicionan el análisis de la segregación para el caso latinoamericano son básicamente cuatro: 1) el papel atribuido al mercado no regulado del suelo; 2) los patrones culturales de las élites latinoamericanas; 3) las regulaciones impuestas por las políticas públicas de planificación; y 4) el crecimiento explosivo de la población urbana.

Respecto al primer factor, es posible hablar de una presión ejercida por el mercado no regulado del suelo, conjuntándose con una deficiente política pública y una sociedad dispuesta -quizá de manera inconsciente- a formar parte del juego del mercado, generando o exacerbando las características del fenómeno segregativo. Lungo y Baires sostienen que:

La segregación es favorecida por diversos factores vinculados al funcionamiento de los mercados de suelo: restricciones de oferta, niveles de precios, lógicas de localización de actividades comerciales y residenciales que favorecen la expulsión de los pobres y la exclusividad de residencia a distinta escala, liberalización del crecimiento urbano o marcos de regulación que estimulan la fragmentación y segregación urbanas [Lungo y Baires, 2001, citados en Arriagada y Rodríguez, 2003: 35-36].

En términos generales, se trata de componentes ligados al sistema capitalista, evidenciándose la importancia de la regulación del mercado de suelo como factor clave para detener la segregación urbana y sus consecuencias negativas sobre el territorio, pero sobre todo para las sociedades.

Acerca de la relación entre segregación y mercados de suelo, Sabatini (2003b) afirma que el precio del suelo, de estar determinado por su uso, se convierte en un factor que excluye usos; esto es debido a que los propietarios 
fijan su precio en relación a los usos esperados, de tal manera que cuando un área se ve ocupada por residentes de más altos ingresos, surge el fenómeno especulativo al alzar los precios del suelo con base en el mejor uso probable, lo cual constituye una barrera para la llegada de grupos de menores ingresos, proceso que denomina "propagación espacial de la especulación con suelos". Por otra parte, el autor menciona la subordinación de los constructores de la ciudad a la estructura de precios del suelo, de tal manera que los invasores ilegales han preferido situarse en terrenos de bajo valor comercial, para así evitar la represión por parte del Estado que les haga abandonar los terrenos ocupados. De igual manera los organismos gubernamentales, así como las inmobiliarias privadas, han asentado a los pobres donde ya hay pobres, en suelos de bajo valor con el fin de abaratar los costos de sus proyectos, alimentándose así el ciclo de la segregación en las ciudades latinoamericanas.

Por otra parte, el mismo autor se refiere al segundo factor, la imitación de patrones culturales por parte de las élites latinoamericanas, que han buscado recrear las realidades de los países desarrollados, volviéndose imitadoras de conductas y patrones. Ello acusa una debilidad en la identidad social de dichos grupos, lo que conduce a exacerbar la segregación como respuesta a la amenaza de su identidad (Sabatini, 2003b).

El tercer factor mencionado es la incidencia de las políticas públicas en materia de vivienda y de desarrollo urbano (Monkkonen, 2012), así como, más generalmente, en relación con la localización de la inversión pública. Dentro de éstas se encuentran las regulaciones impuestas desde los instrumentos de planificación, en los que se considera que hay excesos y vacíos que, lejos de atenuarla, "colaboran" a exacerbar la segregación (Arriagada y Rodríguez, 2003).

Por último, y no menos importante, las ciudades latinoamericanas experimentan en las últimas décadas crecimientos demográficos explosivos, en parte por haber realizado una transición demográfica muy tardía y muy concentrada en el tiempo. Este crecimiento demográfico se acompaña por una urbanización creciente (producto de la migración campo-ciudad), dando lugar a ciudades que multiplican en pocas décadas su población. En este contexto, el crecimiento acumulativo favorece el desarrollo de procesos segregativos y su visibilización, en comparación a ciudades europeas con un desarrollo urbano mucho más maduro.

Al hablar de las diferencias y matices existentes en las manifestaciones de la segregación residencial para el caso latinoamericano, en comparación con las expresadas en países de Europa y en Estados Unidos, quizás la más marcada sea en relación con este último país. La literatura estadounidense 
muestra que los procesos de ocupación de la ciudad por parte de los sectores de más bajos ingresos se sitúan en las áreas centrales, debido al desarrollo suburbano basado en el uso del automóvil y la regulación del uso del suelo en las áreas suburbanas, combinado con el incremento de los ingresos de las clases medias y altas durante la segunda mitad del siglo XX. En cambio, en la región latinoamericana el proceso de rápida urbanización que se vivió en ese mismo periodo produjo una proliferación de asentamientos informales de vivienda en la periferia, no sin después ser "consumidas" por la ciudad, derivando en su incorporación formal en ésta (Mieszkowski y Mills, 1993; Mangin, 1967; Sabatini, 2003b; Ford, 1996 y Ward, 2001, citados en Monkkonen, 2012). La falta de políticas previsoras en relación al rápido proceso de urbanización que se vivió en prácticamente todo el territorio latinoamericano a partir de la segunda mitad del siglo XX, hizo evidente la falta de preparación e inexperiencia de los estados para afrontar en muchos aspectos este éxodo rural y urbano.

Fue así como dicho patrón de segregación empezó a consolidarse en Latinoamérica, mismo que tiende a parecerse más al de las ciudades compactas europeas, donde los grupos sociales de mayores ingresos y la mejor edificación y arquitectura se concentran en las áreas centrales, donde también el suelo es más caro (Sabatini, 2003b).

Se habría generado así el patrón de segregación residencial latinoamericano, que puede resumirse en tres características principales: 1) los grupos de ingresos elevados así como los grupos medios ascendentes se concentran en un área de la ciudad, generalmente con un vértice en el centro histórico, y se mueven hacia la periferia en una dirección definida; 2) los grupos de ingresos más bajos ocupan áreas de baja densidad en las zonas periféricas y mal servidas, pero también espacios deteriorados cercanos al centro; y 3) existe una mayor homogeneidad socioeconómica en los barrios de bajos ingresos en contraste con una mayor diversidad social en los barrios de alta renta (Sabatini, 2003b; Griffin y Ford, 1980, citado en Monkkonen, 2012). Además, y para el caso mexicano, Monkkonen (2012) sugiere que existe la particularidad de la dispersión de los hogares de bajos ingresos sobre el territorio de sus ciudades. En contraste con las ideas generalmente aceptadas,

la mayoría de los hogares de bajos ingresos en el México urbano vive en áreas de la ciudad cuya densidad es relativamente baja, en profundo contraste con la imagen estereotipada de barrios bajos urbanos densos, que se debe en cierta medida a la tendencia de los investigadores urbanos a enfocarse en las grandes áreas metropolitanas. De hecho, los hogares de ingresos altos en las ciudades mexicanas tienen densidades más altas que los hogares de bajos ingresos. Esto 
es lógico, dada su tendencia a vivir en las partes centrales de la ciudad y la intensidad más alta de desarrollo en tierras localizadas más centralmente [Monkkonen, 2012: 127].

No obstante, Bähr y Mertins (1993), Janoschka (2002) y Borsdorf(2003) han demostrado que el modelo latinoamericano de ciudad y sus formas de segregación residencial no son estáticas, pues las pautas de localización de las clases o estratos socioeconómicos han ido evolucionando con el tiempo, pasando del modelo "tradicional" centro-periferia propio de la colonia, donde el hábitat más o menos central determinaba la posición social de los habitantes, a la "ciudad fragmentada" actual (Borsdorf, 2003), caracterizada por la diversificación social de la periferia debido a la dispersión de la clase alta y media, generalmente bajo la forma de gated communities o fraccionamientos cerrados (incluso también para la clase obrera; véase, para México, García Peralta y Hofer, 2006). Simultáneamente, partes del centro histórico se especializan en funciones comerciales, vaciándose parcialmente de su población, mientras que otros sectores experimentan una renovación urbanística que da lugar a procesos de gentrificación (Janoschka y Sequera, 2014; Salinas, 2013). Pese a estos cambios, hay autores como Ribeiro que, pese a defender hace unas décadas la transformación del modelo de ciudad latinoamericana con la consiguiente pérdida de vigencia del modelo tradicional (Ribeiro y Lago, 1995), sostiene actualmente la validez y el predominio de una versión modernizada del esquema centro-periferia de segregación residencial en las ciudades de América Latina (Ribeiro, 2016), pues considera más bien secundaria la fragmentación y la diversificación social de las periferias, en línea con lo que piensan otros autores como Roberts y Wilson (2009) o Rubalcava y Schteingart (2012), estas últimas para el caso de México.

El debate entre los partidarios de la ciudad "dual" -concepto ya utilizado por Castells (1991) y Sassen (2001), aunque aplicado a una dimensión ocupacional más que territorial-y de la ciudad "fragmentada" (Duhau, 2011; Sabatini, 2003a y 2003b; Borsdorf, 2003; Janoschka, 2002) ha articulado en los últimos años los estudios sobre la segregación socioespacial en América Latina y sobre las pautas de localización urbana de los grupos sociales, y por ello ha conocido aportaciones de muchos de los autores que han investigado el tema en tiempos recientes, entre cuyos nombres -además de todos los ya mencionados- se puede destacar a Aguilar y Mateos (2012), Alegría (2004), Garrocho y Campos (2013), Sánchez-Peña (2012), Sobrino (2012) y Solís y Puga (2011), entre otros.

Cabe por último insistir en que el estudio de la segregación ha estado dominado por la focalización en las grandes urbes o en territorios metropo- 
litanos, siendo escasos los análisis de ciudades medias o pequeñas. De ahí el interés de analizar a Culiacán como ejemplo de éstas, para así verificar si el patrón de segregación residencial en las grandes ciudades latinoamericanas, así como los recientes procesos de cambio de dicho patrón por el paso del modelo tradicional centro-periferia al de la ciudad fragmentada (esa será nuestra hipótesis de partida) también se están experimentado en las ciudades de menor tamaño.

\section{Metodología y fuentes de datos estadísticos}

Para estudiar la segregación socioespacial se deben utilizar unidades espaciales intraurbanas, por ello se emplean los datos de los Censos de Población y Vivienda de 2000 y 2010, llevados a cabo por el Instituto Nacional de Estadística y Geografía (INEGI, 2000 y 2010), con un nivel de desagregación por Área Geoestadística Básica (AGEB), que corresponde a los sectores censales situados en el área urbana de la ciudad. Según el INEGI, una AGEB urbana es un área geográfica ocupada por un conjunto de manzanas perfectamente delimitadas por calles, avenidas, andadores o cualquier otro rasgo de fácil identificación en el terreno, y cuyo uso del suelo es principalmente habitacional, industrial, de servicios o comercial; y sólo son asignadas en el interior de las zonas urbanas con población mayor o igual a 2500 habitantes y en las cabeceras municipales. En la elección de la unidad de análisis óptima juega un papel determinante la disponibilidad y posibilidad de acceso a los datos censales. Las bases de datos censales cuentan con diversos indicadores, con un total de 177 variables en la del Censo de 2000, mientras la del 2010 contiene 190. Entre ambos censos existen variaciones en la disponibilidad de variables, por un lado, más el problema de la no continuidad, con variables que fueron recogidas durante el Censo de 2000 y que no se captaron en 2010, además de que en 2010 se añadieron nuevas. Esto implica que algunas de las variables consideradas útiles se tuvieron que reconstruir a partir de los datos censales disponibles; es decir, se utilizaron dos o más variables de un censo para generar la equivalencia correspondiente con una o más variables del otro, en los casos en lo que esto fue posible. En este sentido, las variables utilizadas en cada uno se detallan en el Anexo, variables que se eligieron de acuerdo con el análisis teórico realizado y que guardan relación con la situación de bienestar de los individuos.

En la realización de los cálculos se utilizaron técnicas de análisis demográfico y de estadística descriptiva. Para construir los índices de segregación se utilizó el programa Geo-Segregation Analyzer, desarrollado por Apparicio 
y Petkevich (2006), ${ }^{1}$ mientras que para el análisis espacial se utilizaron softwares de Sistemas de Información Geográfica.

Se miden, de esta forma, cuatro de las cinco dimensiones básicas de la segregación identificadas por Massey y Denton (1988): las de igualdad, exposición, concentración y agrupamiento, que son las más estudiadas y que de forma complementaria explican los niveles de segregación sociorresidencial encontrados en una ciudad. De la amplia variedad de indicadores que contempla cada una de estas dimensiones, se escogieron los siguientes índices, que se encuentran entre los más utilizados en la literatura científica:

1) El Índice de Segregación (IS) de Duncan (Duncan y Duncan, 1955), que compara la distribución de un grupo de población $x$ en relación a la población total $t$, con valores en una escala entre 0 (las dos poblaciones se distribuyen exactamente de la misma forma) y 1, que indica la máxima segregación (no comparten territorio alguno). Su formulación es:'

$$
\mathrm{IS}=\sum_{i=1}^{n}\left|\frac{\mathrm{x}_{i}}{X}-\frac{t_{i}-\mathrm{x}_{i}}{T-X}\right| \quad 0 \leq \mathrm{IS} \leq 1
$$

2) El Índice de Aislamiento (xPx), definido por Bell (1954), que en una escala entre 0 y 1 mide la probabilidad de que un individuo comparta la unidad espacial con otro individuo de su mismo grupo (véase Martori y Hoberg, 2004):

$$
\mathrm{xPx}=\sum_{i=1}^{n}\left(\frac{\mathrm{x}_{i}}{X}\right)\left(\frac{\mathrm{x}_{i}}{t_{i}}\right) \quad 0 \leq \mathrm{xPx} \leq 1
$$

3) El Índice Delta de Duncan (DEL) (Hoover, 1941; Duncan et al., 1961), donde en este caso se calcula la distribución de un grupo en relación al área que ocupa en el conjunto de la ciudad, siendo $x$ el grupo de población y $a$ el área donde reside, con resultados en una escala de 0 a 1 :

$$
\mathrm{DEL}=\frac{1}{2} \sum_{i=1}^{n}\left|\frac{x_{i}}{X}-\frac{a_{i}}{A}\right| \quad 0 \leq \mathrm{DEL} \leq 1
$$

${ }^{1}$ El W en: http://geoseganalyzer.ucs.inrs.ca/ 
4) Finalmente, se calcula un índice de agrupación espacial, que expresa la media de individuos del grupo $x$ de cada sección como proporción de la población total de las secciones vecinas. Es el Índice de Agrupamiento Absoluto (ACL) (Massey y Denton, 1988; Dacey, 1968; Geary, 1954):

$$
\begin{gathered}
\mathrm{ACL}=\left\{\left[\sum_{i=1}^{n}\left(\frac{\mathrm{x}_{i}}{X}\right) \sum_{j=1}^{n}\left(C_{i j} X_{j}\right)\right]-\left[\mathrm{X} / \mathrm{n}^{2} \sum_{i=1}^{n} \sum_{j=1}^{n} C_{i j}\right]\right\} / \\
\left\{\left[\sum_{i=1}^{n}\left(\frac{\mathrm{x}_{i}}{X}\right) \sum_{j=1}^{n}\left(C_{i j} t_{j}\right)\right]-\left[\mathrm{X} / \mathrm{n}^{2} \sum_{i=1}^{n} \sum_{j=1}^{n} C_{i j}\right]\right\} \quad 0 \leq \mathrm{ACL} \leq 1
\end{gathered}
$$

donde $x_{i}$ es la población del grupo minoritario en la sección censal $i ; X$ la población total del grupo minoritario en el municipio; $t_{i}$ la población total en la sección $i$; $T$ la población total del municipio; $n$ el número de secciones del municipio; $A$ la superficie de la ciudad; $c_{i j}$ el valor de la celda de la matriz de contigüidad binaria entre las unidades espaciales $i$ y $j$, con 1 cuando $i$ y $j$ son contiguas y 0 cuando no lo son.

\section{El territorio y sus características}

\subsection{Las características del ámbito del estudio}

Para la realización de este estudio se consideró el área urbana que ocupa Culiacán, la cual contiene un total de 682712 habitantes en una extensión de $218.91 \mathrm{~km}^{2}$, de acuerdo con lo que indica el Plan Director de Desarrollo Urbano de Culiacán 2010 (PDDUC 2010); territorio que, cabe aclarar, incluye tanto áreas ocupadas como reservas territoriales y previsión de nuevo crecimiento. El área urbana de Culiacán tiene una densidad de 3118.64 habs./ $\mathrm{km}^{2}$, según el INEGI (2010), y está conformada por 387 AGEB y con un total de 467 colonias en su área urbana.

El Consejo Nacional de Población (Conapo, 2003) menciona que las ciudades medias, como es el caso de Culiacán, son las que crecen más rápido en términos demográficos; sin embargo, también presentan -sobre todo durante las últimas décadas- tendencias hacia la disminución del crecimiento natural y un incipiente envejecimiento de la estructura de su población. 
Culiacán se encuentra entre las primeras veinte ciudades más pobladas del país (el lugar 19, con datos del INEGI, 2010), con un crecimiento poblacional que ha ido de la mano del desarrollo económico y urbano de las últimas décadas, y con diversos procesos de urbanización de la cabecera municipal, alimentada por la migración de los poblados y sindicaturas hacia ésta.

Culiacán presentó un rápido incremento poblacional, intensificado hacia mediados del siglo XX (Gráfica 1), aunque en cifras absolutas está experimentando tanto ahora como en la década de los setenta crecimientos mayores. Dicho crecimiento se debió a numerosos factores, entre los que figuran el mejoramiento de las técnicas agrícolas y la infraestructura de riego que produjo la intensificación de las migraciones campo-ciudad. Paulatinamente el crecimiento se fue volviendo cada vez más lento, principalmente debido a que la economía, dependiente de la agricultura casi en su totalidad durante las décadas anteriores, se diversificó hacia otros sectores productivos. A pesar de ello, la ciudad sumó 135 mil nuevos habitantes durante la última década, con un ritmo de crecimiento del 2.24 por ciento.

\subsection{La distribución espacial de la población en Culiacán}

La distribución de la población entre los dos censos muestra que las AGEB situadas en zonas más céntricas, que ya eran de las menos pobladas en el año 2000, han continuado perdiendo población, debido en parte a su conversión en áreas mayoritariamente comerciales. Sin embargo, las zonas menos pobladas son, tanto en un año como en el otro, las más periféricas, de poblamiento reciente y quizás todavía no consolidado (Mapa 1). Por el contrario, en el año 2010, y a diferencia de lo que sucedía en el 2000, la población se encuentra más dispersa sobre el territorio, encontrándose AGEB con más de 5000 habitantes en las periferias sur, este y oeste (pero no en los barrios más periféricos), siendo la periferia norte la única que no cuenta con tales concentraciones demográficas.

Más importante aún es vincular el proceso de envejecimiento con los cambios observados en el territorio de la ciudad. Al respecto, es importante apuntar lo que Sabatini (2003a) señala acerca del patrón tradicional de segregación de las ciudades de América Latina, que muestra una mayor presencia de niños en la periferia de las ciudades, acompañada de una mayor proporción de adultos en las áreas centrales.

El grupo de edad mayor, de 65 años y más, en la última década creció en términos absolutos y relativos, significando $4.98 \%$ de la población de la ciudad en 2010. Esta cifra, por sí sola, no explica el proceso de envejeci- 


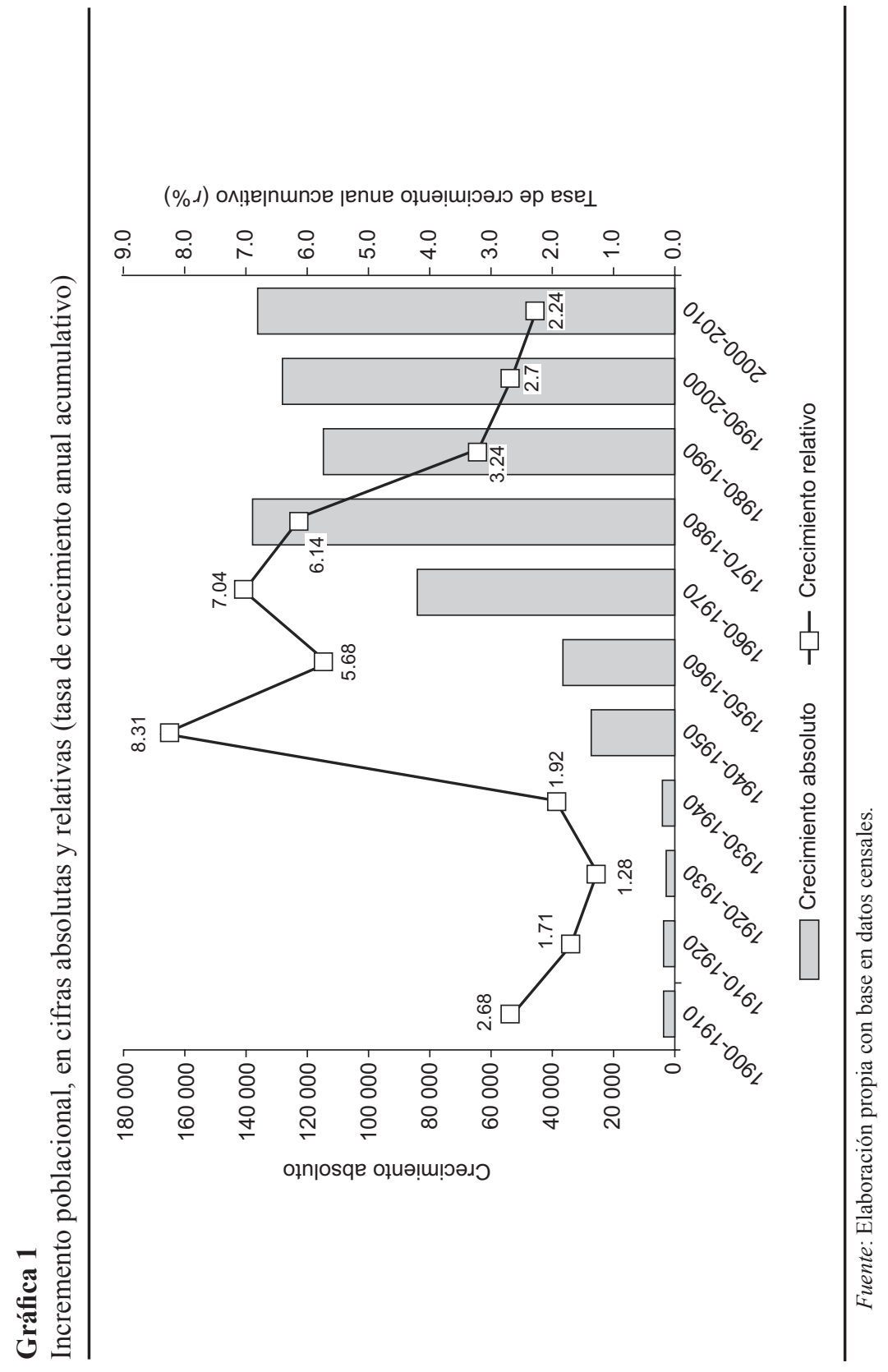




\section{Mapa 1}

Distribución de la población en Culiacán por AGEB, 2000 y 2010

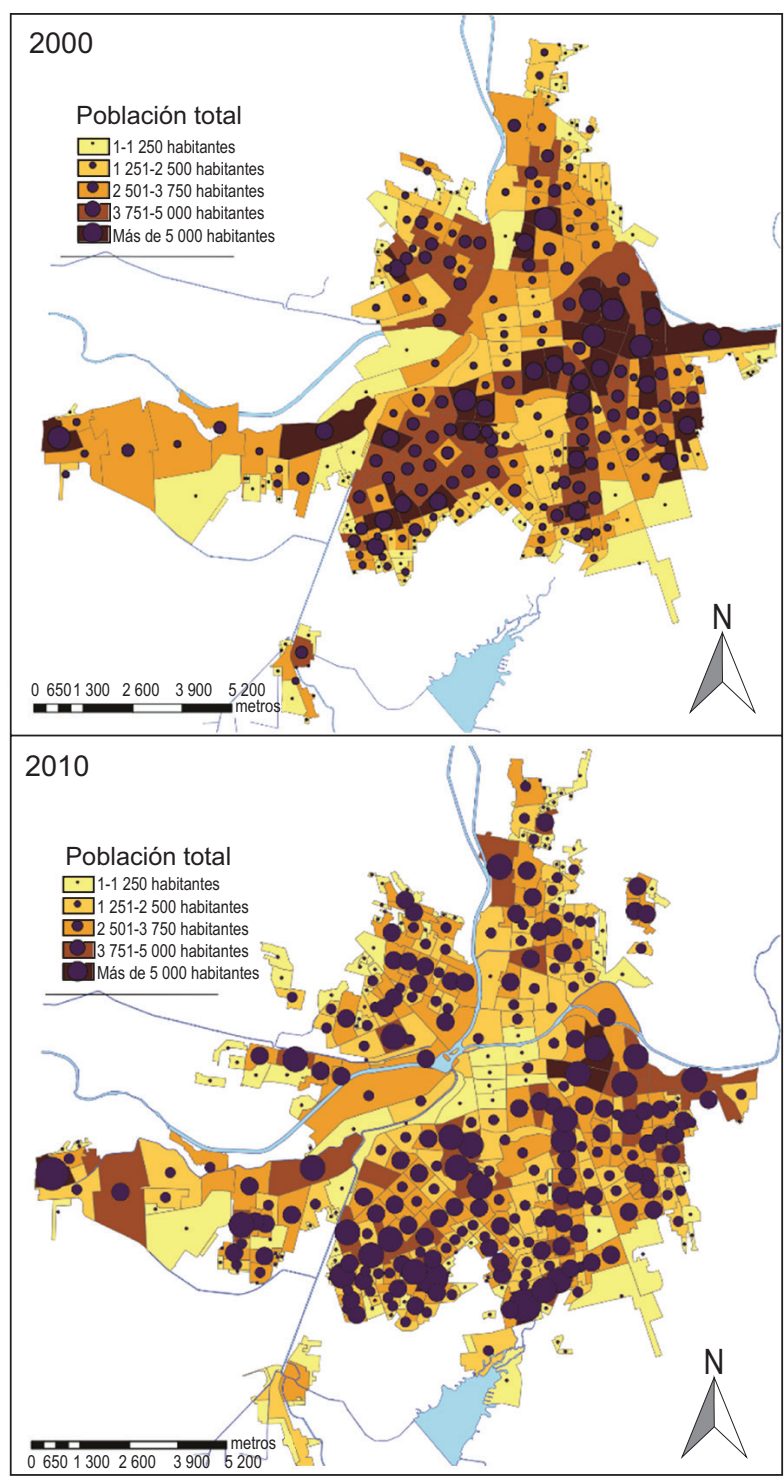

Fuente: Elaboración propia con base en datos censales (INEGI, 2000 y 2010). 


\section{Cuadro 1}

Evolución del peso de los grandes grupos de edad en Culiacán, 1990-2010

\begin{tabular}{lrrr}
\hline Población & \multicolumn{1}{c}{$\mathbf{1 9 9 0}$} & \multicolumn{1}{c}{$\mathbf{2 0 0 0}$} & \multicolumn{1}{c}{$\mathbf{2 0 1 0}$} \\
\hline 0-14 años & 136965 & 175824 & 189508 \\
15 a 64 años & 264646 & 349149 & 459222 \\
65 y más & 13435 & 22057 & 33982 \\
Total & 415046 & 547030 & 682712 \\
\hline \% total & & & \\
$0-14$ años & $33.00 \%$ & $32.14 \%$ & $27.76 \%$ \\
15 a 64 años & $63.76 \%$ & $63.83 \%$ & $67.26 \%$ \\
65 y más & $3.24 \%$ & $4.03 \%$ & $4.98 \%$ \\
\hline
\end{tabular}

Fuente: Elaboración propia con base en datos censales (INEGI, 1990, 2000 y 2010).

miento que está experimentando la ciudad, pero si se analiza el crecimiento relativo desde 1990, se puede ver una clara tendencia al alza (Cuadro 1). En este sentido, el índice de envejecimiento o ratio entre la población mayor y la infantil se incrementó en 5.39 puntos porcentuales durante la última década, de $12.54 \%$ en 2000 a $17.93 \%$ en 2010 , vislumbrando procesos como la declinación de la ciudad central de la que se hablará con mayor profundidad más adelante.

Tanto en el año 2000 como en el 2010 el mayor peso porcentual de la población mayor se situaba en el área central (donde algunas AGEB incluso tienen valores entre el 20 y el $25 \%$ de la población en 2010), aunque se observa un progresivo envejecimiento que se propaga concéntricamente desde las áreas más centrales, pero que no alcanza aún a las zonas periféricas, que siguen siendo las más jóvenes ya que en éstas residen (y se desplazan) familias jóvenes (Mapa 2).

\subsection{El decrecimiento de la población en las áreas centrales}

Al contrario de los procesos observados en la América anglosajona, y más en concordancia con las ciudades europeas, en América Latina las áreas centrales han estado tradicionalmente habitadas por los grupos de más altos ingresos. Sin embargo, desde mediados del siglo pasado estos grupos tienden a salir de los centros históricos. Diversos estudios señalan que es a partir de 1990 cuando se produce una inflexión con la aparición de signos de suburbanización (Torres, 2001; Rodríguez, 2002). Así pues, las áreas centrales de 


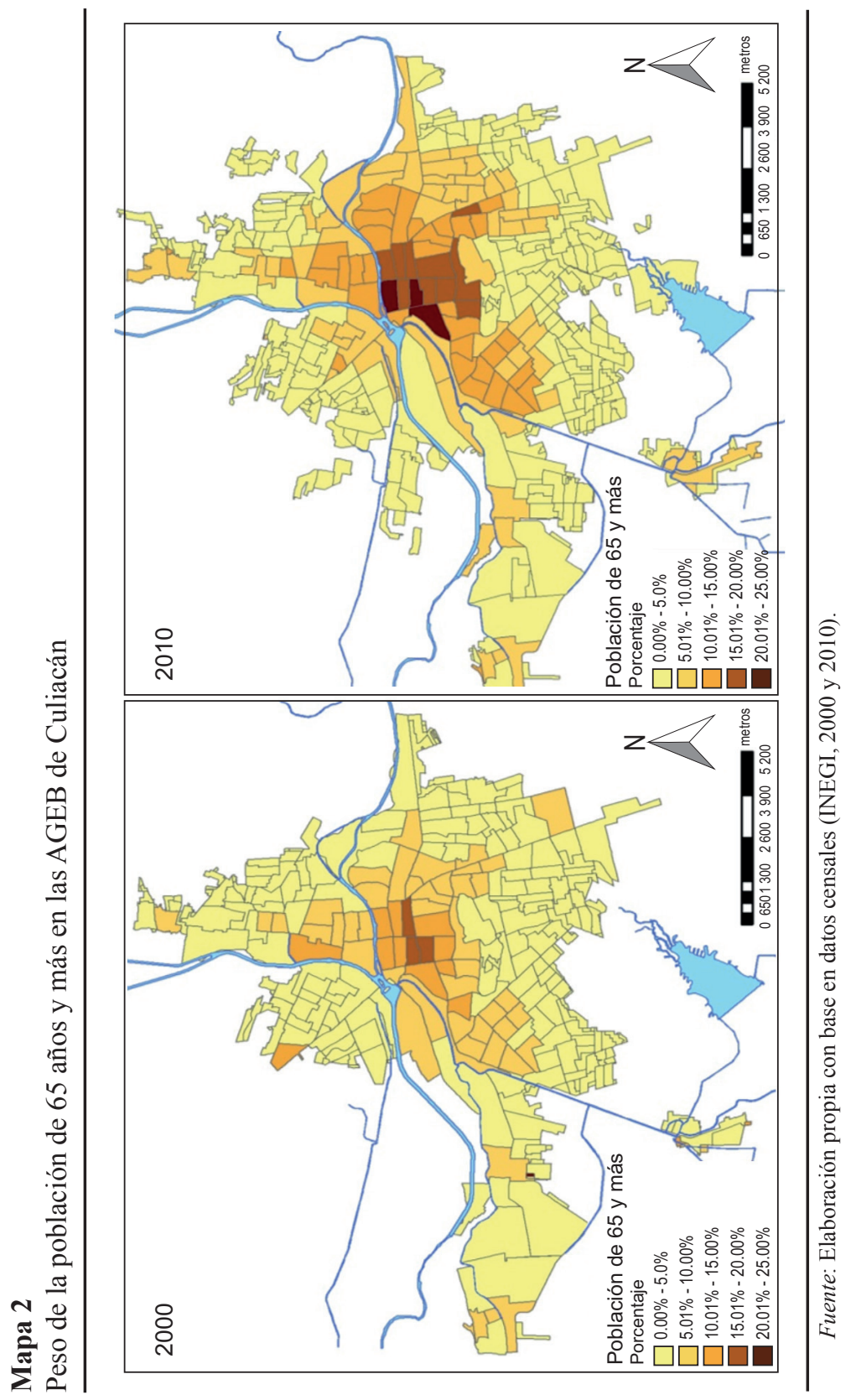


las grandes ciudades latinoamericanas, y particularmente las de México, han sufrido desde hace varias décadas un proceso de continuo despoblamiento. Paquette y Delaunay (2009) argumentan que esto se debe a una desconcentración generalizada de la población, que se produce desde la zona de urbanización más antigua y mejor consolidada, en beneficio de contornos urbanos más recientes y de las periferias, generalmente con procesos de rápida expansión. Es necesario vincular este proceso con las dinámicas familiares y el ciclo de vida de los hogares, en el que la salida de los hijos de dichos hogares juega un papel fundamental en la conformación de las periferias (y en el descenso de población de los centros).

El caso de Culiacán es un claro ejemplo de esta dinámica. Se observa un decrecimiento de las áreas centrales y, al mismo tiempo, de crecimiento de las áreas periféricas (Mapa 3), aunque no se tengan disponibles datos de movilidad interna para sustentar dicha situación. El perímetro del Centro Histórico de la ciudad, marcado con líneas discontinuas, queda evidentemente abarcado por la dinámica de decrecimiento, que se extiende más allá de sus límites, en un área muy extensa en relación al conjunto de la ciudad. En el Mapa 3 es posible observar que las zonas que crecen por encima de la $(r)$ media, de 2.2 para este periodo, se sitúan en un anillo periférico de la ciudad, donde también se incluyen las AGEB que se expanden ${ }^{2}$ y las de nueva creación en relación al año 2000 .

Para el caso de Culiacán, este proceso de despoblamiento de las áreas centrales no sólo está vinculado con lo expuesto por Paquette y Delaunay (2009), sino que se identifican otros factores como el envejecimiento de la población y el cambio en la configuración de los hogares y el promedio de sus ocupantes. Así también, este fenómeno está relacionado con la menor capacidad de gestión y control urbano por parte del Estado, que deriva en una deficiente planeación urbana y reglamentación que oriente el desarrollo de la ciudad, condición bajo la cual el suelo tradicionalmente agrícola que rodeaba al área urbana pasó a convertirse en suelo urbano, por ser económicamente más rentable para sus propietarios, y también como producto de la presión que las grandes desarrolladoras inmobiliarias ejercen sobre estos propietarios y los gobiernos mismos (Janoschka, 2002; Sabatini, 2003a; Domínguez, 2017). De la misma manera, se advierte una tendencia de conversión de las áreas centrales en áreas comerciales que, ante la falta de una planeación efectiva, deprecian la vivienda en estos sectores a favor de usos comercialmente más rentables. Esta tendencia encontrada en Culiacán abo-

${ }^{2}$ Es decir, que en el censo de 2010 cambian su configuración espacial para fusionarse con otras AGEB o se incrementan en tamaño respecto a la misma del censo del año 2000 (análisis propio). 


\section{Mapa 3}

Zonas que crecen y decrecen, por AGEB, 2010

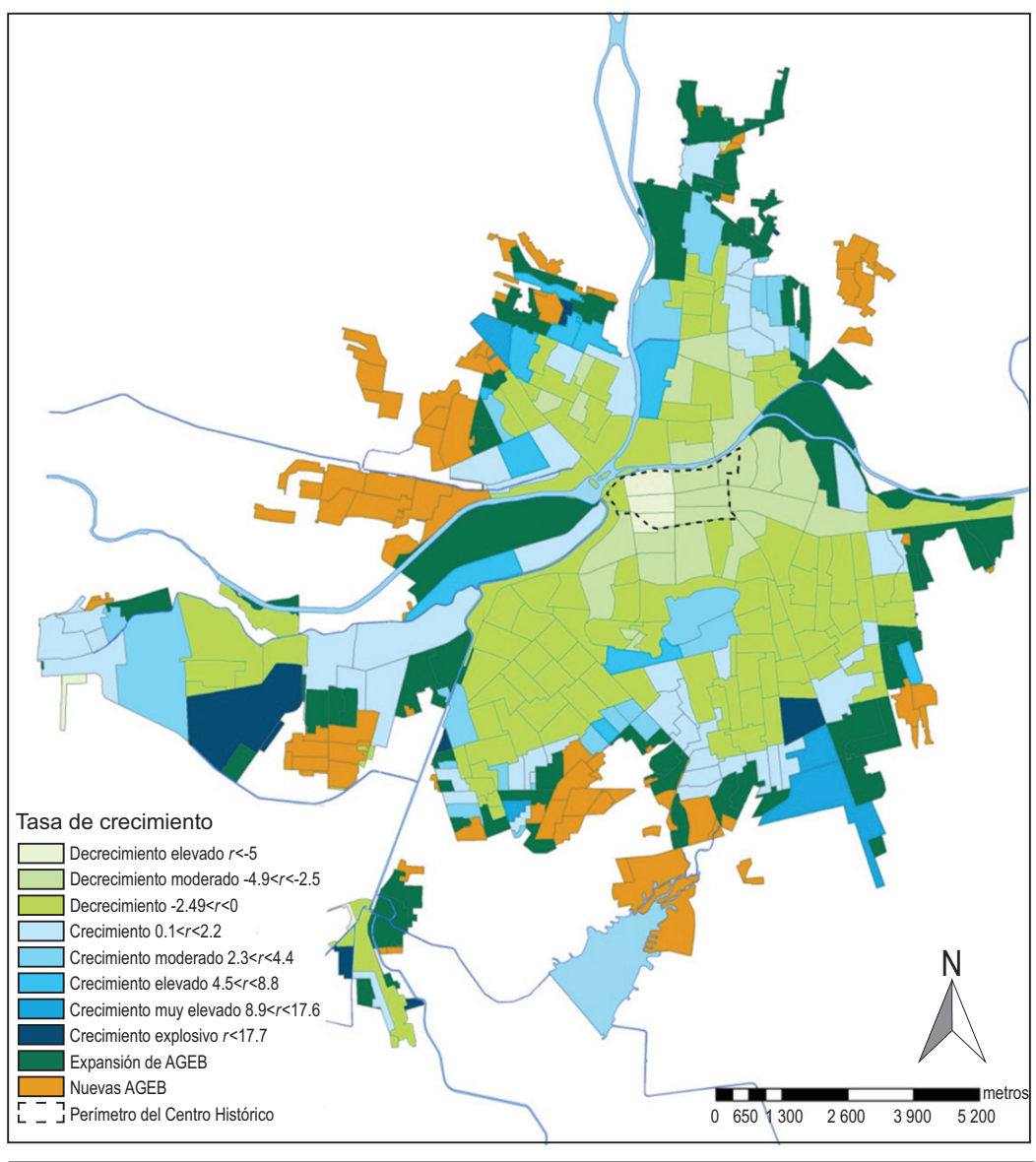

Fuente: Elaboración propia con base en datos censales (INEGI, 2010).

na al debate sobre el tradicional modelo espacial de las ciudades latinoamericanas junto con los procesos de segregación socioespacial que en éstas toman parte, toda vez que en la literatura abundan las afirmaciones acerca de la discrepancia entre la conformación periférica de las ciudades latinoamericanas y las de Estados Unidos (Tuirán, 2000; Sabatini, 2003a; Rodríguez, 2002; Rodríguez y Arraigada, 2004), apuntándose como principal diferencia el abandono de la ciudad central de las ciudades estadounidenses en favor 
de usos no residenciales, mayormente comerciales, por parte de los grupos medios o más acomodados. En el caso de América Latina las áreas centrales siguen siendo concentradoras del bienestar y la riqueza. En este sentido, en Culiacán podemos observar una coincidencia con estas tendencias características de las ciudades estadounidenses, por lo que sería interesante poder profundizar sobre las dimensiones y causas de este poblamiento central. Cabe señalar que, desde diversos estudios, se advierten cambios en estas tendencias tradicionales de crecimiento de las ciudades latinoamericanas y de localización de la segregación. Estos cambios espaciales muestran una tendencia de elección de las áreas periféricas para la ubicación de los nuevos hogares en lugar de la reutilización de las áreas centrales. Es en estas periferias donde el mercado del suelo y la vivienda ha abierto nuevas posibilidades de intervención que significan alternativas de desarrollo residencial para las élites o grupos medios altos, provocando cambios en los tradicionales patrones de segregación (Sabatini, 2003a; Janoshcka, 2002; Rodríguez, 2002; Rodríguez y Arriagada, 2004; Borsdorf, 2003).

\subsection{Apuntes sobre la conformación histórica de las periferias de Culiacán}

El proceso de crecimiento de Culiacán ha estado acompañado por la existencia de grandes vacíos urbanos en las zonas interiores ya consolidadas, la ocupación no programada del suelo en las periferias y la transformación de las comunidades consideradas ejidales en territorios urbanos; ahí se han generado asentamientos de carácter popular que, carentes de servicios e infraestructuras básicas, inician una lucha contra el gobierno local para que, primeramente, les permita permanecer en dichos territorios y, posteriormente, se les provea de los servicios e infraestructuras necesarias.

Resulta inevitable hacer mención del papel que la construcción de fraccionamientos cerrados juega en la conformación de la periferia de Culiacán como parte y condicionante del proceso segregativo. Este tipo de fraccionamientos ha pasado a formar parte de la tipología de vivienda habitual de $\mathrm{Cu}-$ liacán al menos en las dos últimas décadas, surgido a partir de una combinación de factores. En parte como una antítesis a los niveles de inseguridad que durante cierto tiempo han predominado en la ciudad y, por otro lado, como respuesta a una elevada demanda de vivienda por parte de la población -predominantemente de clase media- que le permita "mejorar" sus condiciones de vida. Esta tipología constructiva, que se desarrolla paralela a la conversión de más de tres mil hectáreas de suelo rural a urbano en los últimos treinta años, 
se apunta como característica del crecimiento horizontal de las áreas urbanas, donde cabe hacer mención que éstas se han situado mayormente en la periferia, por ser el lugar económicamente más atractivo para los desarrolladores. De tal manera se ha creado una "periferia polifacética", en la que es posible visualizar pedazos de ciudad con un alto grado de desarrollo, equipamiento o infraestructura al lado de otros fragmentos de ciudad severamente deteriorados.

\section{Análisis del patrón espacial de localización socioeconómica y de la segregación en Culiacán}

El punto central de este trabajo sobre la segregación en Culiacán consistió en realizar una radiografía de las principales características socioeconómicas que están condicionando el emplazamiento de la población sobre el territorio, con el fin de encontrar los patrones sobre los cuales se están desarrollando los procesos de segregación socioespacial. Para ello se analiza en primer lugar la distribución espacial de la población en relación a indicadores fuertemente vinculados a su condición socioeconómica -como son la situación del empleo, la educación, el estado de la vivienda-, o en relación a los bienes y servicios con los que cuenta, o las personas que la habitan.

\subsection{La actividad económica de la población}

La no inclusión de la variable del salario percibido en el Censo de 2010 imposibilita la comparación diacrónica de la evolución de la segregación, motivo por el cual esta variable no se utiliza en nuestro análisis. Como contrapartida, se pueden establecer pautas territoriales con base en la población económicamente activa ${ }^{3} \mathrm{y}$ la población ocupada, ${ }^{4}$ que son las únicas variables que aparecen en ambos censos, variables a priori válidas ${ }^{5}$ para generar un

3 Según el Censo de Población y Vivienda 2010, "Personas de 12 años y más que trabajaron; tenían trabajo, pero no trabajaron; o buscaron trabajo en la semana de referencia" en la que se realizó el censo (INEGI, 2010).

${ }^{4}$ Personas de 12 a 130 años de edad que trabajaron o que no trabajaron, pero sí tenían trabajo en la semana de referencia.

5 Como limitantes, tenemos que la primera no aporta muchos elementos para entender el comportamiento de la población en el territorio en términos económicos, mientras la segunda puede ocultar en sus resultados situaciones de retiro o fin de la vida laboral. Sin embargo, hemos decidido presentar el análisis, puesto que refuerza el hallazgo del despoblamiento del área central de la ciudad presentado previamente, junto con su envejecimiento, situaciones importantes por destacar al hablar de la distribución espacial de la población y la forma urbana de la ciudad. 
contraste en la distribución de los ingresos en el territorio en función de una situación favorable y su contraparte. En realidad, el mapa sobre la distribución de la población desocupada, que no se incluye por razones de espacio, no permite advertir tendencias claras de distribución espacial, aunque sí una perpetuación de las pautas observadas en 2000 en relación a 2010. Por el contrario, el mapa sobre población ocupada (Mapa 4) lo que muestra es un patrón de envejecimiento, ya que permite identificar un área central con la menor proporción de población ocupada que se debe a este factor y no a una situación de desempleo, pues como lo veremos en los análisis posteriores, ésta es una zona que guarda una situación favorable al respecto de los demás aspectos analizados. Por el contrario, las zonas periféricas, más jóvenes, son las que están concentrando los mayores porcentajes de población ocupada.

\section{Mapa 4}

Distribución espacial de la población ocupada en las AGEB, 2010

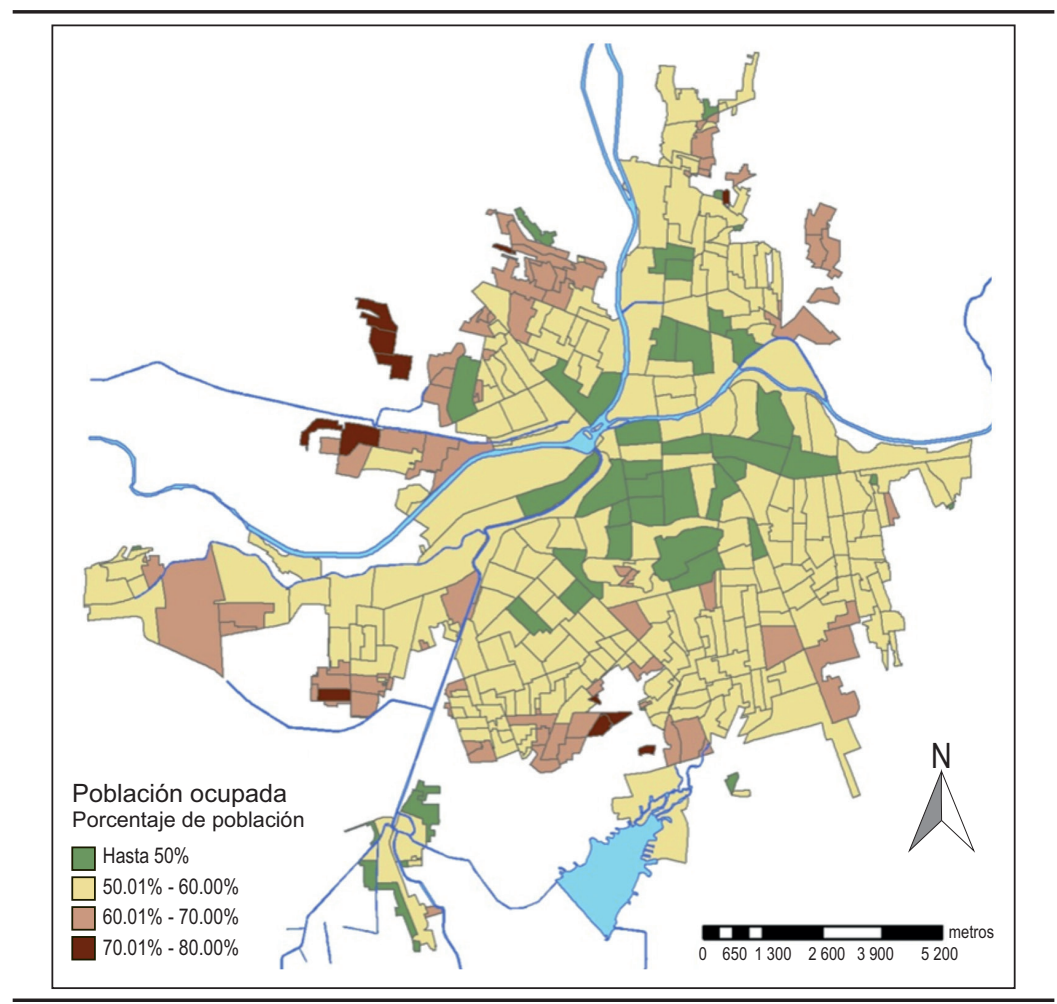

Fuente: Elaboración propia con base en datos censales (INEGI, 2010).

Estudios Demográficos y Urbanos, vol. 32, núm. 3 (96), 2017, pp. 547-591 


\subsection{La segregación según el nivel de estudios}

Tradicionalmente en los estudios sobre segregación se ha puesto especial atención en el nivel de estudios como condicionante de ésta, puesto que se ha establecido una conexión entre dicho nivel y el tipo de ocupación, relacionándose directamente con el rango de ingresos (Rubiales et al., 2012). El nivel de instrucción escolar en sus grados inferiores es uno de los principales indicadores utilizados para prever el riesgo de exclusión social (Bayona, 2006). A pesar de que pueden presentarse discordancias con esta afirmación en casos muy específicos, en los países en vías de desarrollo, como México, el nivel de instrucción sigue manteniendo un lugar preponderante en los patrones de asentamiento de la población sobre el territorio, al seguir condicionando la movilidad social (Pérez Tamayo, 2013).

En cuanto a la distribución espacial de las categorías de nivel de instrucción, se eligió representar categorías comparables entre los dos censos disponibles, de manera que pueda apreciarse la evolución territorial de la misma. El Mapa 5 muestra cómo se distribuye espacialmente en las AGEB la población que no tiene instrucción completada. A partir de ésta es posible apreciar que en los dos periodos comparados la población analizada se distribuye de manera similar. Sin embargo la situación se está agudizando negativamente en el interior de las AGEB, puesto que las de la periferia norte, este y sur, que en el año 2000 presentaban una situación desfavorecedora, concentrando del 30 al $40 \%$ de la población sin nivel educativo básico completado, en el último censo ascienden a niveles de entre el 40 y $50 \%$. Para ambos años, las áreas centrales, así como la periferia oeste y suroeste para 2010, son las que presentan la situación más benéfica. Con base en el análisis anterior se ha elegido mostrar la distribución territorial de la población que no asiste a la escuela entre el grupo de 6 a 14 años, la cual representa la edad de la educación básica obligatoria y que cuando no se lleva a cabo, se vincula con situaciones relacionadas con pobreza, discapacidad, abandono o similares, fuertemente ligadas con una segregación del tipo negativo, que de continuar, dificulta el escalamiento social de este grupo en particular, toda vez que los mejores salarios se asocian a mejores niveles de instrucción escolar (Mapa 6).

El Mapa 7 refleja el grado de escolaridad promedio de la AGEB, y está realizado tomando en cuenta los años promedio de instrucción escolar de la unidad censal y trasladándolo al grado de instrucción que corresponde. Podemos apreciar que se muestra una marcada concentración de los niveles más altos en las áreas centrales, situación que se extiende hacia el sector oeste en 2010. En el año 2000 el territorio mostraba la prevalencia de los 


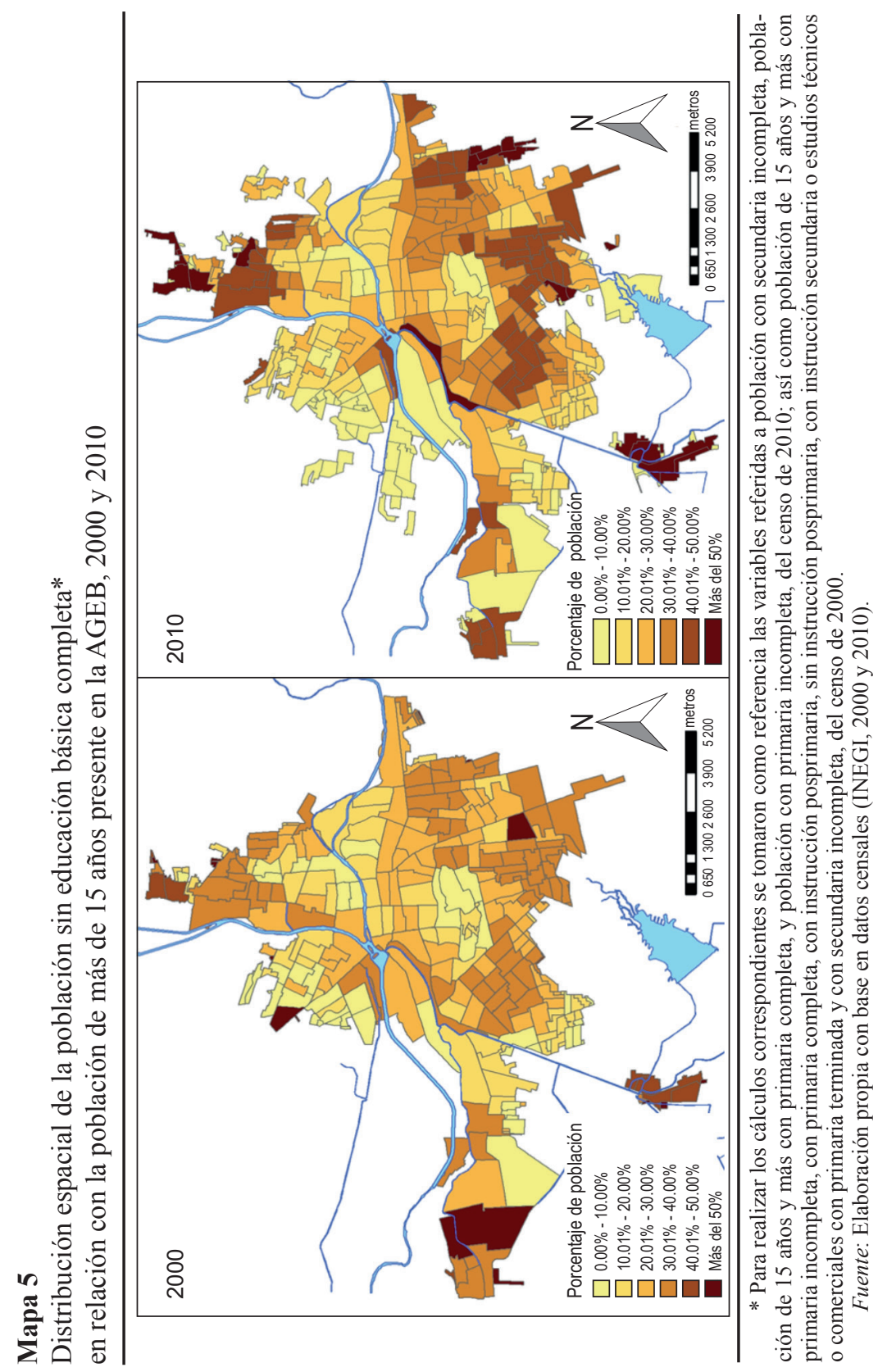




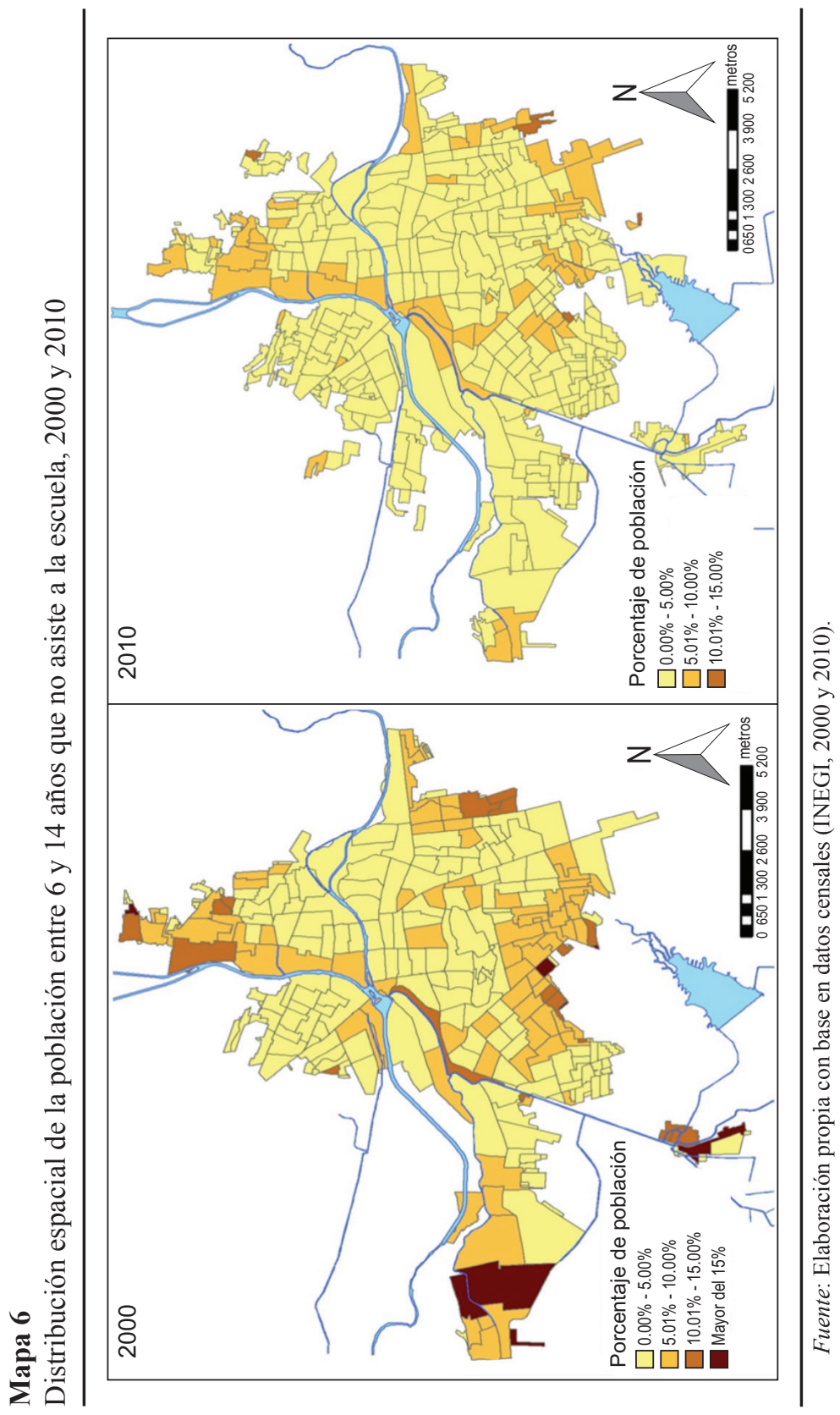


estudios de nivel secundaria, situación que cambia en 2010 al reflejarse un incremento de sectores con instrucción de nivel bachillerato y profesional, y decremento en los que predomina el nivel de secundaria, así como el de primaria. La situación para las periferias norte, este y un área al suroeste de la ciudad llamada El Diez, corresponde a las categorías de los niveles de instrucción más bajos.

A partir del Mapa 7 es posible afirmar que el nivel de estudios alcanzado por la población de Culiacán presenta una tendencia hacia la mejoría. Sin embargo, su distribución en el territorio presenta pautas de localización muy claras y que tienden a consolidarse. A este respecto cabe señalar que el sector oeste, de relativa nueva creación, está caracterizado por la construcción de fraccionamientos de vivienda residencial de tipo medio, en su mayoría promovidos por inmobiliarias privadas y que se ofertan principalmente entre parejas jóvenes de poder adquisitivo de tipo medio.

\subsection{Las características de las viviendas en Culiacán}

La ciudad de Culiacán se ha conformado tradicionalmente por el crecimiento alrededor de su centro histórico de la mano de un fuerte incremento poblacional. Ante este hecho, la oferta de vivienda en la segunda mitad del siglo pasado se vio rebasada por la demanda existente, lo que provocó, además de la proliferación de los asentamientos irregulares, que la configuración espacial de la ciudad estuviera notoriamente marcada por barrios de autoconstrucción, no atribuyéndose éstos a un cierto sector socioeconómico de la ciudad, sino que fue parte constante de la dinámica de crecimiento del parque inmobiliario. Así pues, se puede observar un territorio fragmentado en su configuración arquitectónica y que, si bien es posible identificar los barrios por la predominancia de cierta homogeneidad visual, presenta hacia el interior notables diferencias que revelan las disparidades presentadas en su configuración social.

Las variables censales que dan cuenta de las características de las viviendas presentan variaciones entre los ejercicios censales del periodo. No obstante, a partir de los datos presentados en el Cuadro 2, es posible advertir un comportamiento hacia la mejora de sus condiciones constructivas hacia 2010, así como de posesión de bienes dentro de los hogares, puesto que el porcentaje que no cuenta con ningún bien se ve reducido 0.28 puntos porcentuales en 2010. No así con la situación de hacinamiento, que prácticamente dobla su proporción al pasar del 18.6 al 33.6\%, hecho particularmente significativo en un contexto de fuerte crecimiento del parque inmobi- 


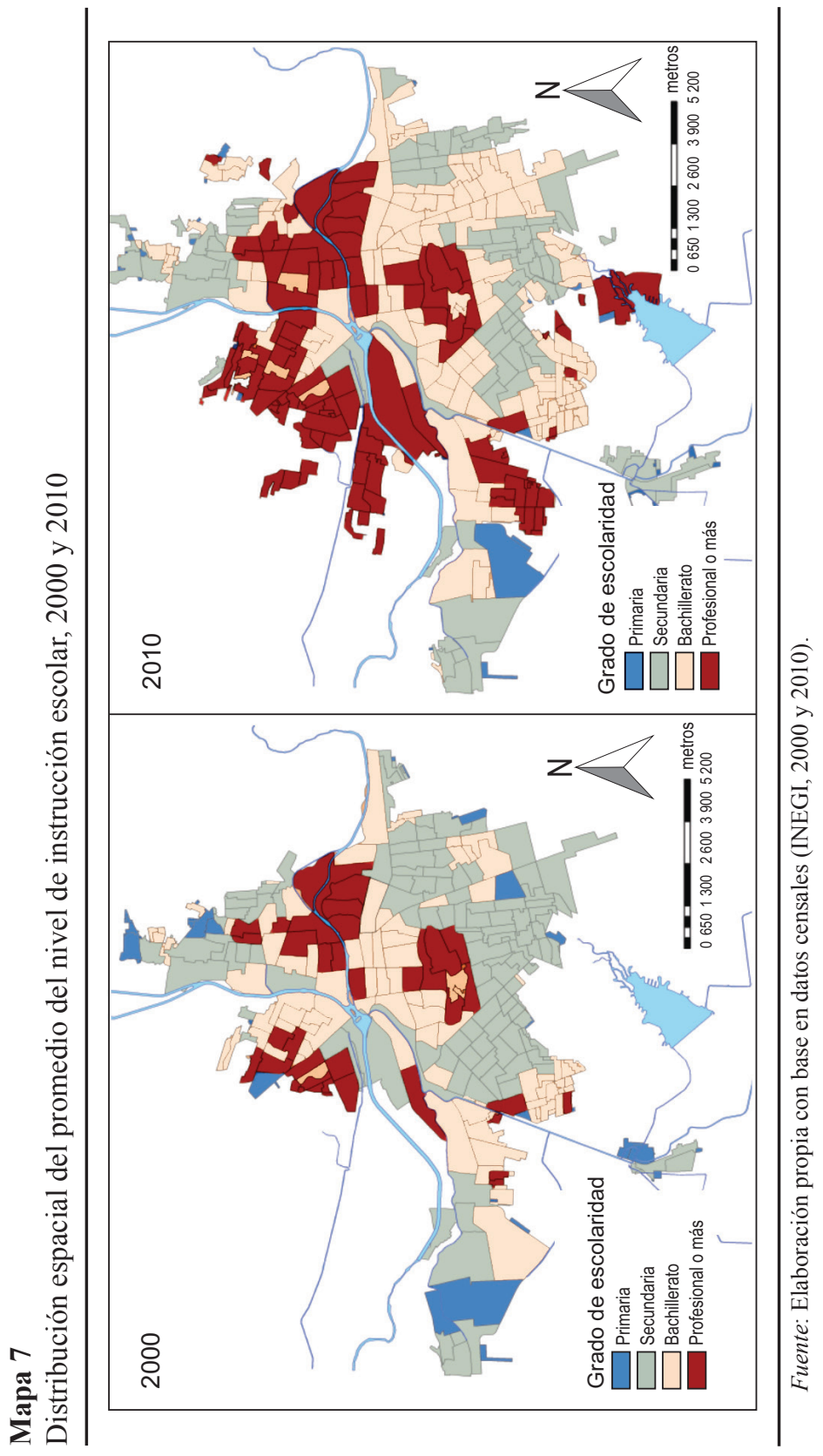




\section{Cuadro 2}

Estado de la vivienda en Culiacán, 2000 y 2010

\begin{tabular}{lcc}
\hline Tipo de vivienda & $\mathbf{2 0 0 0}$ & $\mathbf{2 0 1 0}$ \\
\hline Sin ningún bien* & $1.55 \%$ & $0.28 \%$ \\
Sin ningún servicio & $1.97 \%$ & Sin datos \\
Con algún nivel de hacinamiento & $18.64 \%$ & $33.6 \%$ \\
Con techos de materiales ligeros o precarios & $8.65 \%$ & Sin datos \\
Con piso de tierra & $10.46 \%$ & $3.0 \%$ \\
\hline
\end{tabular}

* Viviendas particulares habitadas que no disponen de radio, televisión, refrigerador, lavadora, automóvil, computadora, teléfono fijo, celular ni internet.

Fuente: Elaboración propia con base en datos censales (INEGI, 2000 y 2010).

liario y reducción del promedio de ocupantes por hogar, situación que sugiere la existencia de varios escenarios que se conjuntan y producen este resultado. La reducción en el número de cuartos en las viviendas, así como del tamaño de las mismas, es una cuestión que está asociada al máximo aprovechamiento del suelo por parte de los desarrolladores inmobiliarios, lo que ha generado constantes críticas en la opinión pública acerca de la disminución del tamaño de las viviendas, así como debates en torno al tamaño conveniente para que una familia tenga la superficie necesaria para realizar sus actividades de manera adecuada. Dicha situación deriva en una paradoja en torno al crecimiento urbano, pues a pesar de que el mercado inmobiliario busca sacar el máximo aprovechamiento del suelo disponible, la constante ha sido la construcción horizontal y de baja densidad sobre un territorio urbano extenso. Esta situación añade un problema de administración del territorio al hacer más difícil, y sobre todo costosa, la dotación de servicios e infraestructuras, así como su posterior mantenimiento al encontrar un área extensa que servir y con una proporción costo/cobertura en términos de densidad muy rebasada por las capacidades financieras de la administración. Porque, a pesar de que con el incremento de la participación privada en el mercado inmobiliario, éste haya tenido que asumir parte de los gastos en la dotación de infraestructura de los desarrollos que construye, generalmente se trata de intervenciones de baja calidad constructiva, lo que generalmente deja a las periferias en una situación de desventaja en este aspecto en relación con las áreas centrales ya consolidadas y con una buena dotación de equipamiento público. Al respecto la bibliografía señala que la segregación se alimenta de la desigualdad de dotación de equipamientos, puesto que la concentración espacial de grupos con diferente capacidad de tributación y pago por bienes públicos locales puede aumentar la desigualdad intraurbana 
y reforzar la diferenciación de la ciudad en zonas mejor equipadas que concentran a la población de mayores recursos frente a zonas pobres con una precaria base de equipamientos y espacios colectivos (Wassmer, 2001; Arriagada y Rodríguez, 2003).

En el Mapa 8 observamos cómo las pautas de localización de las viviendas hacinadas siguen siendo las mismas en 2010 que en 2000: tienden a concentrarse en las periferias norte, sur y este, lo que sugiere una agudización de la situación en las viviendas que ya se encontraban hacinadas. Este patrón también se repite en las AGEB contiguas de nueva creación, situación probablemente exacerbada por el incremento poblacional, las parejas jóvenes que tienen hijos, la emancipación tardía o la migración de las áreas rurales aledañas hacia el primer punto de contacto urbano como son las periferias. De nuevo destacan las áreas centrales con la menor concentración de hacinamiento, que coincide con el patrón de hogares más pequeños, despoblamiento y viviendas desocupadas.

\subsection{La segregación desde la perspectiva de los índices de segregación}

Los principales indicadores de segregación calculados se muestran en el Cuadro 3, donde se encuentran dos grandes grupos de variables, a las que llamamos "variables positivas" y "variables negativas". El primer grupo de ellas supone la existencia de condiciones positivas y asociadas a ciertos niveles de segregación que podríamos adjetivar como de "voluntaria" o "elegida" (véase Rubiales et al., 2012). El segundo grupo, en cambio, se relaciona con situaciones de desventaja, las cuales pueden estar exacerbando la segregación de los grupos más desprotegidos. Ambas variables se comparan en los dos periodos analizados y para las categorías donde esto resultó posible.

El resultado de este análisis es la incuestionable existencia de segregación en el área urbana de Culiacán, que se presenta para algunas variables con valores elevados. Sin embargo, sí puede hablarse de una mejoría de las condiciones de su manifestación, justificada por la disminución de la mayoría de los valores de los índices como característica generalizada.

A pesar de ello, dicha mejora podría atribuirse a factores más bien de tipo coyuntural que de índole estructural. Nos referimos, entre otros, a la ralentización del ritmo de crecimiento de la ciudad, que permite en cierta forma que se suavice un poco la presión producida por el proceso de crecimiento acelerado conocido durante las últimas décadas. Por otra parte, se encuentra la expansión de la ciudad y la redistribución de la población dentro de su territorio. También, cabe señalar que para el año 2000 se venían 


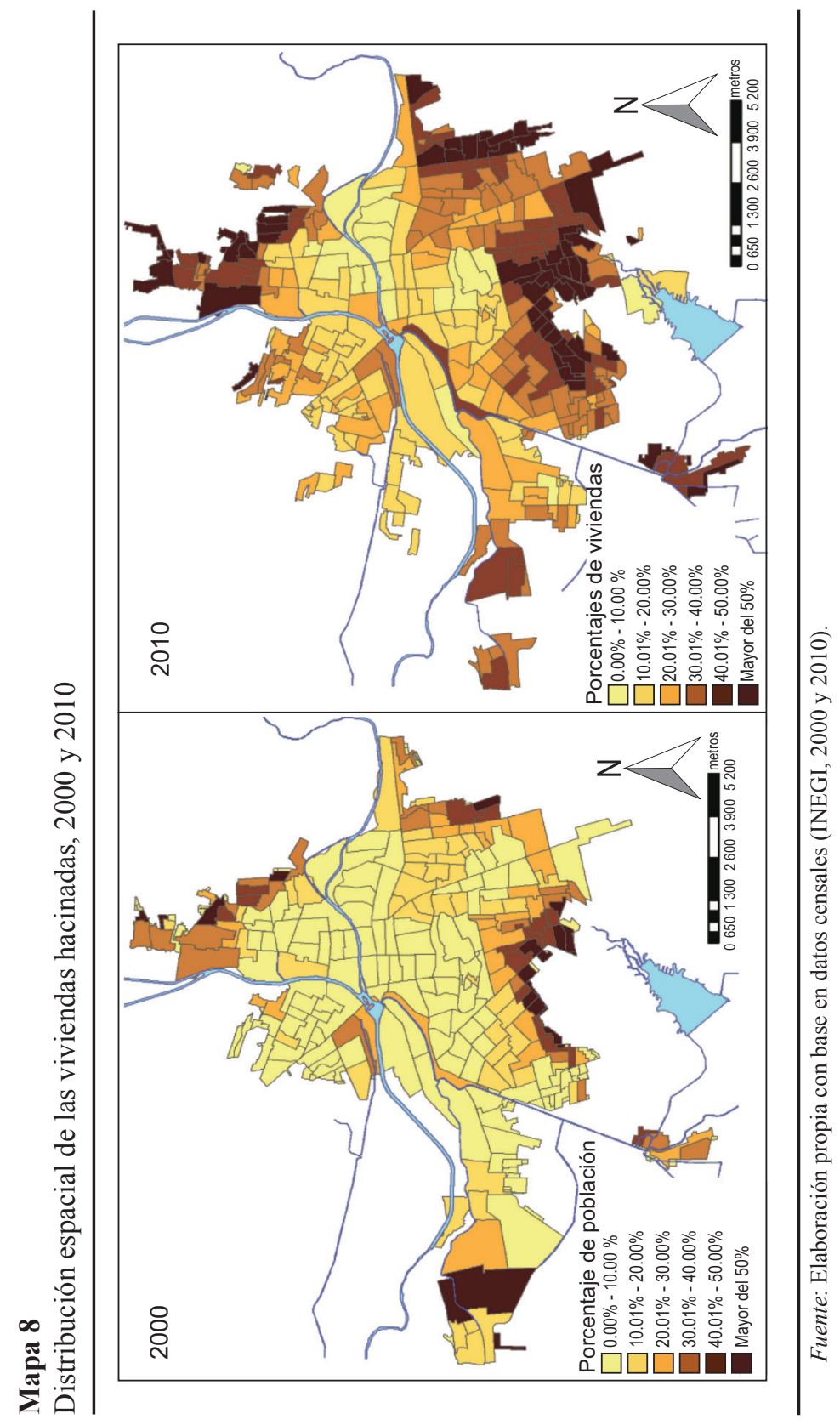




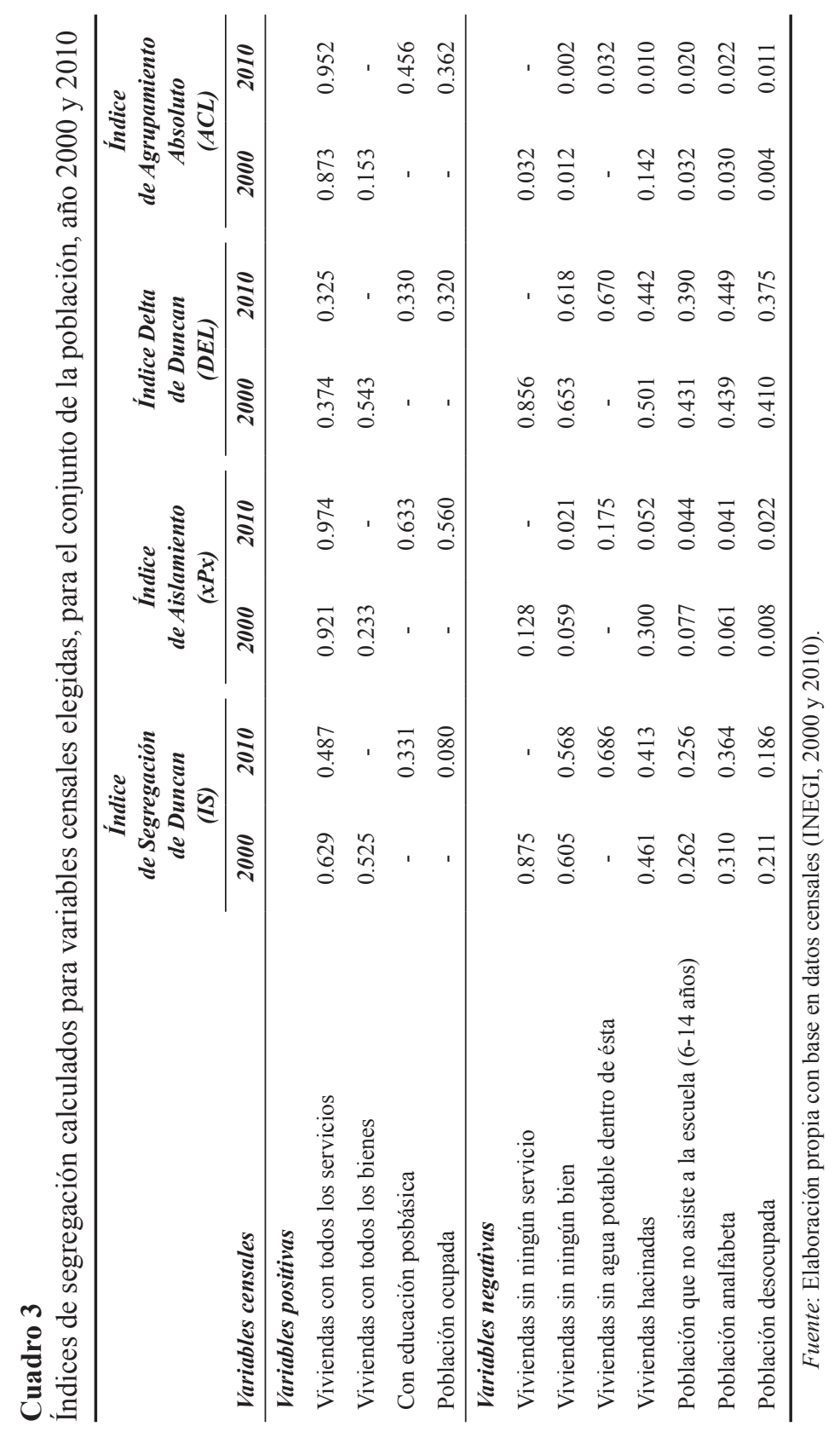


arrastrando las consecuencias de la apertura al experimento neoliberal y que, en gran parte, había llevado al país a vivir la gran crisis mexicana de 1995, contexto bajo el cual las manifestaciones de la segregación tienden a acrecentarse y visibilizarse. Con respecto a este resultado, que remite al conocido problema de escala de la segregación, Aguilar y Mateos (2012), Domínguez (2017), así como Sabatini (2003a), señalan que, a escala micro, el efecto socioespacial de la transformación del patrón espacial de segregación residencial de las ciudades latinoamericanas ha aumentado la segregación, aunque a mayor escala aparentemente disminuye; esto es, se acrecienta la heterogeneidad social o "mezcla social", razón por la cual sugerimos la necesidad de realizar un estudio a escala más pequeña (como la manzana), que permita comparar lo que sucede cuando cambiamos la escala de análisis.

\subsection{Acercamiento a un patrón espacial de la segregación en Culiacán}

A modo de conclusión, y como reflexión y conceptualización territorial de las variables analizadas (entendidas como un conjunto de implicaciones que de manera relacionada y nunca aislada determinan las pautas que sigue el proceso de segregación que sufre la ciudad), se resumen en el Mapa 9 las tendencias territoriales más fuertes identificadas en Culiacán. Creemos que este resultado es de suma utilidad para futuros análisis sobre el proceso estudiado. A partir de esto, es posible identificar zonas o coronas de desarrollo urbano con comportamientos homogéneos y pautas similares.

Así pues, a partir del análisis realizado es posible hablar de un proceso de segregación territorial que para el caso de Culiacán se ha sostenido en términos geográficos en los mismos sectores en el periodo analizado. Es cierto que en 2010 se observan ligeras mejorías en algunos de los indicadores estudiados, pero en general tienden a mantenerse las pautas de segregación, esto es, las diferencias socioeconómicas entre las áreas localizadas. En este sentido, es posible observar que las áreas periféricas de la ciudad son el lugar de concentración de la marginación y la exclusión social. La zona norte (Mapa 9) es la que presenta los niveles más altos de segregación y concentración de "variables negativas", cuenta con bajo nivel de instrucción escolar y un elevado índice de viviendas en situación precaria y con problemas de hacinamiento, así como una fuerte tendencia al establecimiento de asentamientos irregulares; en consecuencia, se habría dado en esta área una agudización de la segregación en el periodo analizado. Por otra parte, en el área central predominan las clases medias-altas y altas, con alto nivel de instrucción escolar. A su vez, presentan una fuerte tendencia a la disminución 


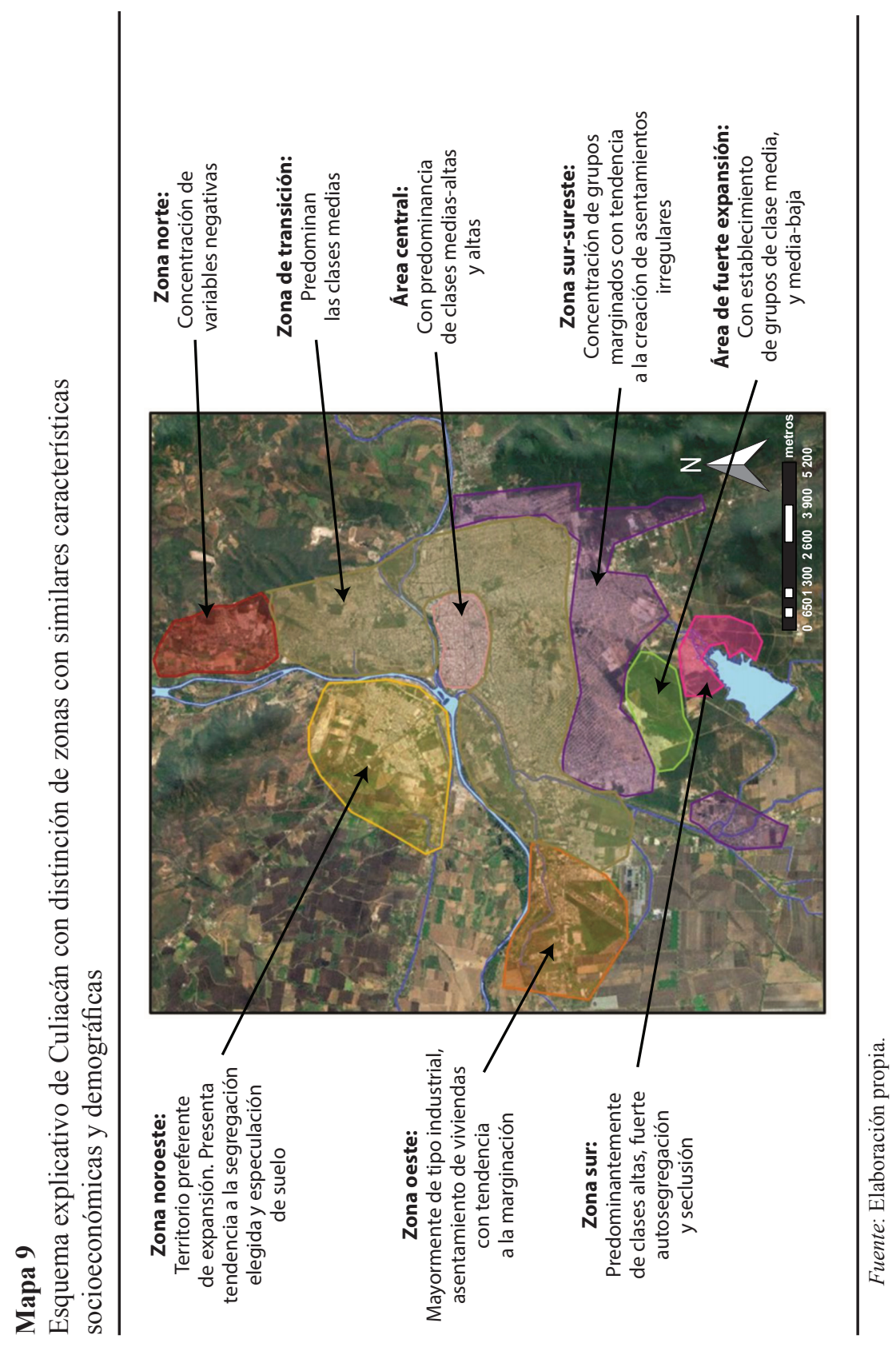


de la población por envejecimiento de las estructuras familiares y reducción del tamaño de los hogares. Alrededor de la zona central se presenta una corona que puede adjetivarse como "zona de transición", con predominancia de clases medias y características sociodemográficas de tipo promedio. La zona noroeste es actualmente el territorio preferente de expansión y a su vez es el que se encuentra más expuesto a sufrir fenómenos de especulación del suelo. En esta zona se establecen mayormente las clases media y media-alta, y es una de las áreas donde más se presenta el fenómeno de la segregación elegida y la creación de barrios cerrados. En la parte sur y sureste, incluyendo el sector que se marca en el PDDUC $2010^{6}$ como El Diez, se establecen dos áreas con características muy homogéneas: por una parte, se encuentra un área en donde se concentran grupos desfavorecidos que, si bien muestran ligeras mejorías en el periodo en relación al conjunto de variables analizadas, presenta una marcada tendencia a la creación de asentamientos irregulares; por otra parte, existe un área de fuerte expansión, preferida por grupos de clase media y media-baja. La zona oeste de la ciudad es el área industrial por tradición, situación que se consolida durante el periodo descrito; asimismo, se exhibe el asentamiento de desarrollos con tendencia a la marginación. Por último, la zona sur, la más meridional de la ciudad, conocida como La Primavera y sus alrededores, se distingue por ser un área predominantemente de clases altas, con una fuerte autosegregación y seclusión.

\section{Conclusiones}

Culiacán, como ejemplo de una ciudad media del sistema de urbes mexicano, parece compartir de forma nítida los grandes procesos y patrones de segregación residencial socioeconómica que se enumeran en la bibliografía internacional al respecto. Se observa una tendencia a la distinción territorial por polarización de la población en términos de su situación socioeconómica. En este contexto, las clases con mejores condiciones socioeconómicas pueden permitirse ubicarse en zonas privilegiadas, con dotación de infraestructuras y servicios, que se localizan generalmente en zonas centrales de la ciudad que se expanden hacia un extremo - el noroeste en el caso de Culiacán-, frecuentemente en forma de fraccionamientos cerrados, reproduciendo el modelo que indica Sabatini (2003b: 4) como "una sola zona de la ciudad con vértice en el Centro Histórico y en una dirección de crecimiento definida hacia la periferia".

${ }^{6}$ Véase www.implanculiacan.gob.mx 
Sin embargo, y en relación con lo anterior, también se observa la presencia del fenómeno que Sabatini (2003b) describe como un cambio en los patrones tradicionales de la segregación como producto de las nuevas dinámicas de las ciudades, destacándose por la apertura de alternativas de desarrollo residencial para las élites o grupos medios-altos fuera de los típicos barrios de rentas altas; es decir, fuera de las áreas tradicionales de concentración de dichos grupos, muchas veces en medio de asentamientos de bajos ingresos. Sería el caso de la gran urbanización cerrada La Primavera, situada en el extremo sur de Culiacán. Por lo tanto, se estaría empezando a dar en una ciudad media como Culiacán el proceso que Borsdorf (2003) califica como de "ciudad fragmentada", caracterizado sobre todo por la existencia, en diferentes zonas del área urbana, de barrios cerrados de clase alta y mediaalta -denominados fraccionamientos cerrados en México, y condominios, barrios privados y urbanizaciones cerradas en otros países latinoamericanosy que es característico de las grandes ciudades latinoamericanas a partir de los años setenta y ochenta del pasado siglo. Por lo tanto, del análisis desarrollado se deduce que en Culiacán, y probablemente también en otras ciudades mexicanas de tamaño intermedio, se estaría dando, como señalaba nuestra hipótesis de partida, un proceso de transición desde el patrón tradicional de segregación residencial de las ciudades latinoamericanas (el denominado modelo centro-periferia) hacia el patrón de ciudad "fragmentada", caracterizado por la creciente diversificación social de la periferia. Esta expansión residencial de una parte de las clases medias y altas hacia zonas periféricas podría hacer pensar que la segregación se está reduciendo; sin embargo, esto no sería más que el reflejo de un problema de escala, porque creemos que a un nivel más micro la segregación residencial estaría aumentando, aunque para poderlo demostrar será necesario realizar nuevas investigaciones a una escala inferior a la AGEB. 


\section{Anexo}

\section{Cuadro A1}

Variables utilizadas para el estudio según los censos de población y vivienda 2000 y 2010

\begin{tabular}{|c|c|}
\hline Censo 2000 & Censo 2010 \\
\hline Población total & Población total \\
\hline Población de 12 años y más & Población de 12 años y más \\
\hline Población de 0 a 14 años & Población de cero a 14 años \\
\hline Población de 15 años & Población de 15 años y más \\
\hline Población de 18 años y más & Población de 18 años y más \\
\hline \multirow[t]{2}{*}{ Población de 6 a 14 años } & - Población de 6 a 11 años \\
\hline & - Población de 12 a 14 años \\
\hline Población de 15 a 64 años & Población de 15 a 64 años \\
\hline Población de 65 años y más & Población de 65 años y más \\
\hline $\begin{array}{l}\text { Población de } 6 \text { a } 14 \text { años que no asiste } \\
\text { a la escuela }\end{array}$ & $\begin{array}{l}\text { - Población de } 6 \text { a } 11 \text { años que no asiste a } \\
\text { la escuela } \\
\text { - Población de } 12 \text { a } 14 \text { años que no asiste } \\
\text { a la escuela }\end{array}$ \\
\hline Población de 15 años y más analfabeta & Población de 15 años y más analfabeta \\
\hline Población de 15 años y más sin escolaridad & Población de 15 años y más sin escolaridad \\
\hline $\begin{array}{l}\text { Población de } 15 \text { años y más con primaria } \\
\text { incompleta }\end{array}$ & $\begin{array}{l}\text { Población de } 15 \text { años y más con primaria } \\
\text { incompleta }\end{array}$ \\
\hline $\begin{array}{l}\text { Población de } 15 \text { años y más con primaria } \\
\text { completa }\end{array}$ & $\begin{array}{l}\text { Población de } 15 \text { años y más con primaria } \\
\text { completa }\end{array}$ \\
\hline $\begin{array}{l}\text { Población de } 15 \text { años y más con secundaria } \\
\text { incompleta }\end{array}$ & $\begin{array}{l}\text { Población de } 15 \text { años y más con secundaria } \\
\text { incompleta }\end{array}$ \\
\hline $\begin{array}{l}\text { Población de } 15 \text { años y más con secundaria } \\
\text { completa }\end{array}$ & $\begin{array}{l}\text { Población de } 15 \text { años y más con secundaria } \\
\text { completa }\end{array}$ \\
\hline $\begin{array}{l}\text { Población de } 18 \text { años y más con educación } \\
\text { posbásica }\end{array}$ & $\begin{array}{l}\text { Población de } 18 \text { años y más con educación } \\
\text { posbásica }\end{array}$ \\
\hline Grado promedio de escolaridad & Grado promedio de escolaridad \\
\hline Población económicamente activa & Población económicamente activa \\
\hline- & Población ocupada \\
\hline Población desocupada & Población desocupada \\
\hline $\begin{array}{l}\text { Población ocupada que recibe menos } \\
\text { de un salario mínimo mensual de ingreso } \\
\text { por trabajo }\end{array}$ & - \\
\hline
\end{tabular}




\section{Cuadro A1}

(concluye)

\begin{tabular}{|c|c|}
\hline Censo 2000 & Censo 2010 \\
\hline $\begin{array}{l}\text { Población ocupada que recibe } 1 \text { y hasta } 2 \\
\text { salarios mínimos mensuales de ingreso } \\
\text { por trabajo }\end{array}$ & - \\
\hline $\begin{array}{l}\text { Población ocupada con más de } 2 \text { y hasta } 5 \\
\text { salarios mínimos mensuales de ingreso } \\
\text { por trabajo }\end{array}$ & - \\
\hline $\begin{array}{l}\text { Población ocupada que recibe más de } 5 \\
\text { salarios mínimos mensuales de ingreso } \\
\text { por trabajo }\end{array}$ & - \\
\hline Total de hogares & Total de hogares censales \\
\hline Población en hogares censales & Población en hogares censales \\
\hline- & Total de viviendas \\
\hline Total de viviendas habitadas & Total de viviendas particulares habitadas \\
\hline Viviendas particulares habitadas & Viviendas particulares habitadas \\
\hline- & Viviendas particulares deshabitadas \\
\hline $\begin{array}{l}\text { Ocupantes en viviendas particulares } \\
\text { habitadas }\end{array}$ & $\begin{array}{l}\text { Ocupantes en viviendas particulares } \\
\text { habitadas }\end{array}$ \\
\hline- & $\begin{array}{l}\text { Promedio de ocupantes en viviendas } \\
\text { particulares habitadas }\end{array}$ \\
\hline $\begin{array}{l}\text { Viviendas particulares que no disponen de } \\
\text { agua entubada, drenaje ni energía eléctrica }\end{array}$ & - \\
\hline $\begin{array}{l}\text { Viviendas particulares con techos de } \\
\text { materiales ligeros, naturales y precarios }\end{array}$ & - \\
\hline $\begin{array}{l}\text { Viviendas habitadas con piso de material } \\
\text { diferente de tierra }\end{array}$ & $\begin{array}{l}\text { Viviendas habitadas con piso de material } \\
\text { diferente de tierra }\end{array}$ \\
\hline $\begin{array}{l}\text { Viviendas particulares habitadas con piso de } \\
\text { tierra }\end{array}$ & $\begin{array}{l}\text { Viviendas particulares habitadas con piso de } \\
\text { tierra }\end{array}$ \\
\hline $\begin{array}{l}\text { Viviendas particulares habitadas con todos } \\
\text { los bienes }\end{array}$ & - \\
\hline $\begin{array}{l}\text { Viviendas particulares habitadas sin ningún } \\
\text { bien }\end{array}$ & $\begin{array}{l}\text { Viviendas particulares habitadas sin ningún } \\
\text { bien }\end{array}$ \\
\hline Viviendas particulares propias & - \\
\hline Viviendas particulares propias pagadas & - \\
\hline Viviendas particulares rentadas & - \\
\hline
\end{tabular}

Fuente: Elaboración propia con base en datos censales (INEGI, 2000 y 2010). 


\section{Bibliografía}

Acosta, Daniel (2015), "Factores sociodemográficos de la estructura residencial del área urbana del municipio de Xalapa", Memoria de investigación, Xalapa, Universidad Veracruzana.

Aguilar, Adrián G. y Pablo Mateos (2012), "Segregación socioeconómica en la Ciudad de México. Análisis con clusters geodemográficos", en Francisco Rodríguez Hernández (coord.), Pobreza, desigualdad y desarrollo: conceptos y aplicaciones, México, UNAM, pp. 177-218.

Alegría, Tito (2004), "Estructura urbana y segregación social: el caso de Tijuana", en Roberto García (comp.), Contradicciones entre planeación y realidades regionales, metropolitanas y socioambientales, Tijuana, Colef/ UANL, pp. 146-182.

Apparicio, Philippe y Valera Petkevich (2006), Geo-Segregation Analyzer: A multiplatform application, version 1.0, Montreal, INRS Disponible en: http://geose ganalyzer.ucs.inrs.ca/

Ariza, Marina y Patricio Solís (2009), "Dinámica socioeconómica y segregación espacial en tres áreas metropolitanas de México, 1990 y 2000", Estudios Sociológicos, vol. 27, núm. 79, pp. 171-209. Disponible en: http://www.redalyc.org/ pdf/598/59820689006.pdf

Arriagada, Camilo y Jorge Rodríguez (2003), Segregación residencial en áreas metropolitanas de América Latina: magnitud, características, evolución e implicaciones de politica, Santiago de Chile, CEPAL.

Bähr, Jürgen y Günter Mertins (1993), "La ciudad en América Latina”, Población y Sociedad, vol. 1, pp. 5-16. Disponible en: http://www.poblacionysociedad.org. ar/archivos/1/P\&S-V1-Bahr-Mertins.pdf

Bayona, Jordi (2006), "Factors sociodemogràfics de la distribució espacial de la població de nacionalitat estrangera a Barcelona", tesis doctoral, Barcelona, Universidad Autónoma de Barcelona.

Borsdorf, Axel (2003), "Cómo modelar el desarrollo y la dinámica de la ciudad latinoamericana", Eure, vol. 29, núm. 86, pp. 37-49. Disponible en: https:// repositorio.uc.cl/bitstream/handle/11534/3935/000340039.pdf?sequence=1

Castells, Manuel (1991), "El auge de la ciudad dual: teoría social y tendencias sociales", Alfoz, núm. 80, pp. 89-103.

Charles, Camille Zubrinsky (2003), "The dynamics of racial residential segregation", Annual Review of Sociology, vol. 29, núm 1, pp. 167-207. Disponible en: http:// www.jstor.org/stable/30036965

CEPAL (2012) Población, territorio y desarrollo sostenible, Santiago de Chile, Comisión Económica para América Latina y el Caribe, LC/L.3474 (CEP.2/3).

CEPAL (2014) Panorama social de América Latina 2014, Santiago de Chile, Comisión Económica para América Latina y el Caribe LC/G.2635-P.

Conapo (2003), La situación demográfica de México, 2003, México, Consejo Nacional de Población. 
Dacey, Michael F. (1968), “A review on measures of contiguity for two and k-color maps”, en Brian J. L. Berry y Duane Francis Marble (coords.), Spatial analysis: A reader in statistical geography, Englewood Cliff, Prentice-Hall, pp. 479-495. Domínguez, Mauricio (2017), "Las dimensiones espaciales de la segregación residencial en la ciudad de Mérida, Yucatán, a principios de siglo XXI", Península, vol. 12, núm. 1, pp. 147-188. Disponible en: http://www.revistas.unam.mx/index. $\mathrm{php} /$ peninsula/article/view/58283

Duhau, Emilio (2011), "La ciudad construida y las nuevas formas de producción del espacio urbano", en Patricia Urquieta (coord.), Ciudades en transformación. Disputas por el espacio, apropiación de la ciudad y prácticas de ciudadanía, La Paz, Bolivia, CIDES-UMSA.

Duncan, Otis, Ray Cuzzort y Beverly Duncan (1961), Statistical geography: Problems in analyzing areal data, Illinois, The Free Press of Glencoe.

Duncan, Otis D. y Beverly Duncan (1955), “A methodological analysis of segregation indexes”, American Sociological Review, vol. 20, núm. 2, pp. 210-217. Disponible en: https://www.jstor.org/stable/2088328?seq=1\#page_scan_tab_contents

Fossett, Mark (2006), "Ethnic preferences, social distance dynamics, and residential segregation: Theoretical explorations using simulation analysis", The Journal of Mathematical Sociology, vol. 30, núm. 3-4, pp. 185-274. Disponible en: http:// www.tandfonline.com/doi/abs/10.1080/00222500500544052

García Peralta, Beatriz y Andreas Hofer (2006), "Housing for the working class on the periphery of Mexico City: A new version of gated communities", Social Justice, vol. 33, núm. 3 (105), pp. 129-141. Disponible en: https://www.jstor. org/stable/29768390?seq=1\#page_scan_tab_contents

Garrocho, Carlos y Juan Campos (2013), "Réquiem por los indicadores no espaciales de segregación residencial”, Papeles de Población, vol. 19, núm. 77, pp. 269-300. Disponible en: www.redalyc.org/pdf/112/11228794011.pdf

Geary, Robert Charles (1954), "The contiguity ratio and statistical mapping", The Incorporated Statistician, vol. 5, núm. 3, pp. 115-146. Disponible en: https:// www.jstor.org/stable/2986645?seq=1\#page_scan_tab_contents

González, Guadalupe M. (2005), "Segregación socioespacial, integración al mercado de trabajo y deterioro de los grupos de ingreso medio en la zona conurbada Zacatecas-Guadalupe, México, 2000”, Papeles de Población, vol. 11, núm. 46, pp. 79-108. Disponible en: http://rppoblacion.uaemex.mx/pp/index.php/papeles depoblacion/article/view/516

Ham, Maarten van, David Manley, Nick Bailey, Ludi Simpson y Duncan Maclennan (coords.) (2012), Neighbourhood effects research: New perspectives, Londres, Springer.

Hoover, Edgar (1941), "Interstate redistribution of population, 1850-1940", Journal of Economic History, vol. 1, núm. 2, pp. 199-205. Disponible en: https://doi. org/10.1017/S0022050700052980

Ibraimovic, Tatjana y Lorenzo Masiero (2014), "Do birds of a feather flock together? The impact of ethnic segregation preferences on neighbourhood choice", Urban 
Studies, vol. 51, núm. 4, pp. 693-711. Disponible en: http://journals.sagepub. com/doi/pdf/10.1177/0042098013493026

INEGI (2000), XII Censo General de Población y Vivienda, México, Instituto Nacional de Estadística y Geografía.

INEGI (2010), Censo de Población y Vivienda, 2010, México, Instituto Nacional de Estadística y Geografía.

Janoschka, Michael (2002), "El nuevo modelo de la ciudad latinoamericana: fragmentación y privatización”, Eure, vol. 28, núm. 85, pp. 11-20. Disponible en: http://www.scielo.cl/scielo.php?script=sci_arttext\&pid=S0250-716120 02008500002

Janoschka, Michael y Jorge Sequera (2014), "Procesos de gentrificación y desplazamiento en América Latina, una perspectiva comparativista", en Juan Michelini (coord.), Desafíos metropolitanos. Un diálogo entre Europa y América Latina, Madrid, Los Libros de la Catarata, pp. 82-104.

Jargowsky, Paul A. (1997), Poverty and place: Ghettos, barrios, and the American city, Nueva York, Russell Sage Foundation.

Kessler, Gabriel y María M. Di Virgilio (2008) “La nueva pobreza urbana. Dinámica global, regional y argentina en las últimas dos décadas", Revista de la CEPAL, núm. 95, pp. 31-50. Disponible en: http://repositorio.cepal.org/bitstream/handle/ 11362/11250/1/095031050_es.pdf

Mangin, William (1967), "Latin American squatter settlements: A problem and a solution", Latin American Research Review, vol. 2, núm. 3, pp. 65-98. Disponible en: https:/www.jstor.org/stable/2502178?seq=1\#page_scan_tab_contents

Martínez, Emilio (1999), "Estudio preliminar", en Robert Ezra Park, La ciudad y otros ensayos de ecología urbana, Barcelona, La Serbal.

Martori, Joan Carles y Karen Hoberg (2004), "Indicadores cuantitativos de segregación residencial. El caso de la población inmigrante en Barcelona”, Geo Crítica. Scripta Nova. Revista Electrónica de Geografía y Ciencias Sociales, vol. 8, núm. 169. Disponible en: http://www.ub.es/geocrit/sn/sn-169.htm

Massey, Douglas S. y Nancy A. Denton (1988), "The dimensions of residential segregation”, Social Forces, vol. 67, núm. 2, pp. 281-315. Disponible en: https:// www.jstor.org/stable/2579183?seq=1\#page_scan_tab_contents

Massey, Douglas S. y Nancy A. Denton (1993), American apartheid: Segregation and the making of the underclass. Cambridge, Harvard University Press.

Mieszkowski, Peter y Edwin. S. Mills (1993), "The causes of metropolitan suburbanization”, Journal of Economic Perspectives, vol. 7, núm. 3, pp. 135-147. Disponible en: http://pubs.aeaweb.org/doi/pdfplus/10.1257/jep.7.3.135

Monkkonen, Paavo (2012), "La segregación residencial en el México urbano: niveles y patrones”, Eure, vol. 38, núm. 114, pp. 125-146. Disponible en: http:// www.scielo.cl/pdf/eure/v38n114/art05.pdf

Nightingale, Carl H. (2012), Segregation: A global history of divided cities, Chicago, University of Chicago Press.

Paquette, Catherine y Daniel Delaunay (2009), "Movilidad residencial y política de 
redensificación: el área central de la Ciudad de México”, Eure, vol. 35, núm. 105, pp. 95-112. Disponible en: http://www.scielo.cl/pdf/eure/v35n105/art05.pdf

PDDUC (2010), Plan Director de Desarrollo Urbano de Culiacán, Culiacán, Instituto Municipal de Planeación Urbana de Culiacán.

Peach, Ceri (1996), "Good segregation, bad segregation", Planning Perspectives, núm. 11, pp. 379-398. Disponible en: http://www.tandfonline.com/doi/pdf/10. 1080/026654396364817? needAccess=true

Pérez Tamayo, B. Nayeli (2013), "Procesos de segregación socioespacial en ciudades medias mexicanas. El caso de Culiacán, México", trabajo final de maestría, Barcelona, Departamento de Geografía.

Porcel, Sergio (2016), "Dinámicas de estructuración sociorresidencial en la Barcelona metropolitana postindustrial. ¿Hacia una ciudad dual o cuarteada?”, tesis doctoral, Barcelona, Universidad de Barcelona, Departamento Sociología.

Ribeiro, Luiz Cesar de Queiroz (2016), "Metamorfoses da ordem urbana da metrópole brasileira: o caso do Rio de Janeiro", Sociologias, vol. 18, núm. 42, pp. 120160. Disponible en: http://www.scielo.br/pdf/soc/v18n42/1517-4522-soc-18-4200120.pdf

Ribeiro, Luiz Cesar de Queiroz y Luciana Correa do Lago (1995), "Restructuring in large Brazilian cities: the centre/periphery model", International Journal of Urban and Regional Research, vol. 19, núm. 3, pp. 369-382. Disponible en: http://dx.doi.org/10.1111/j.1468-2427.1995.tb00514.x

Roberts, Bryan R. y Robert. H. Wilson (coords.) (2009), Urban segregation and governance in the Americas, Nueva York, Palgrave-MacMillan.

Rodríguez, Jorge (2002), Distribución territorial de la población de América Latina y el Caribe. Tendencias, interpretaciones y desafios para las politicas públicas, Santiago de Chile, Celade.

Rodríguez, Jorge y Camilo Arriagada (2004), "Segregación residencial en la ciudad latinoamericana", Eure, vol. 29, núm. 89, pp. 5-24. Disponible en: http://www. scielo.cl/pdf/eure/v30n89/art01.pdf

Rubalcava, Rosa M. y Martha Schteingart (2012), Ciudades divididas, México, El Colegio de México, A.C.

Rubiales, Miguel, Jordi Bayona e Isabel Pujadas (2012), "Patrones espaciales de la segregación residencial en la Región Metropolitana de Barcelona: pautas de segregación de los grupos altos", Scripta Nova: Revista Electrónica de Geografia y Ciencias Sociales, vol. 16, núm. 423. Disponible en: http://www.ub.edu/ geocrit/sn/sn-423.htm

Sabatini, Francisco (1998), "Direcciones para el futuro", en Ricardo Jordán y Daniela Simioni (comps.), "Ciudades intermedias de América Latina y el Caribe: propuestas para la gestión urbana", Documento de Investigación, núm. LC/L.1117, Santiago de Chile, CEPAL / Ministerio de Relaciones Exteriores de Italia. Disponible en: http://repositorio.cepal.org/bitstream/handle/11362/31024/ S9800066 es.pdf.txt 
Sabatini, Francisco (2003a), La segregación social del espacio en las ciudades de América Latina. Washington DC, Banco Interamericano de Desarrollo.

Sabatini, Francisco (2003b), "La segregación social del espacio en las ciudades de América Latina", Documentos del Instituto de Estudios Urbanos, Serie Azul, núm. 35, Santiago de Chile, Pontificia Universidad Católica de Chile. Disponible en https://publications.iadb.org/handle/11319/5324

Salinas, Luis Alberto (2013), "Gentrificación en la ciudad latinoamericana. El caso de Buenos Aires y Ciudad de México”, GeoGraphos, vol. 4, núm. 44, pp. 283-306. Disponible en: https:/web.ua.es/es/revista-geographos-giecryal/documentos/ luis-salinas.pdf?noCache $=1363271617297$

Sampson, Robert J. (2012), Great American city: Chicago and the enduring neighborhood effect, Chicago, University of Chicago Press.

Sánchez Peña, Landy (2012), “Alcances y límites de los métodos de análisis espacial para el estudio de la pobreza urbana”, Papeles de Población, vol. 18, núm. 72, pp. 147-179. Disponible en: http://www.redalyc.org/articulo.oa?id=11223536007

Sassen, Saskia (2001), The global city: New york, London, Tokyo, Princeton, Princeton University Press.

Schelling, Thomas (1978), Micromotives and macrobehavior, Nueva York, WN Norton \& Company.

Schteingart, Martha (2001), "La división social del espacio en las ciudades", Perfiles Latinoamericanos, núm. 19, pp. 13-31. Disponible en: http://www.redalyc.org/ pdf/115/11501902.pdf

Sobrino, Jaime (2012), "Reseña del libro Ciudades divididas: desigualdad y segregación social en México”, Nueva Antropología, vol. 25, núm. 76, pp. 140-142. Disponible en: http://www.redalyc.org/articulo.oa?id=15924294009

Solís, Patricio e Ismael Puga (2011), “Efectos del nivel socioeconómico de la zona de residencia sobre el proceso de estratificación social en Monterrey", Estudios Demográficos y Urbanos, vol. 26, núm. 2 (77), pp. 233-265. Disponible en: http:// estudiosdemograficosyurbanos.colmex.mx/index.php/edu/article/view/ $1383 / 1376$

Torres, Horacio (2001), "Cambios socioterritoriales en Buenos Aires durante la década de 1990”, Eure, vol. 27, núm. 80, pp. 33-56. Disponible en: http://www. scielo.cl/scielo.php?script=sci_arttext\&pid=S0250-71612001008000003

Tuirán, Rodolfo (2000), Tendencias recientes de la movilidad territorial en algunas zonas metropolitanas de México, Mercado de Valores, vol. 60, núm. 3, pp. 47-61.

Wacquant, Loïc J.D. (1997), "Three pernicious premises in the study of the American ghetto", International Journal of Urban and Regional Research, vol. 21, pp. 341353. Disponible en: http://onlinelibrary.wiley.com/doi/10.1111/1468-2427.00076/ epdf

Wassmer, Robert (2001), "The economics of the causes and benefits/costs of urban spatial segregation", trabajo presentado en el International Seminar on Segregation in the City, Cambridge, Massachusetts, Lincoln Institute of Land Policy, 26 a 28 de julio. 
White, Michael J. (1983), "The measurement of spatial segregation", American Journal of Sociology, vol. 88, núm. 5, pp. 1008-1018. Disponible en: https:// www.jstor.org/stable/2779449?seq=1\#page_scan_tab_contents

Wilson, William J. (1987), The truly disadvantaged, Chicago, University of Chicago Press.

\section{Acerca de los autores}

B. Nayeli Pérez-Tamayo es licenciada en Arquitectura por la Universidad Autónoma de Sinaloa, y maestra en Planificación Territorial y Gestión Ambiental por la Universidad de Barcelona. Actualmente estudia el doctorado en Geografía, Planificación Territorial y Gestión Ambiental en la Universidad de Barcelona. Es integrante externa del grupo de investigación consolidado Territorio, Población y Ciudadanía, coordinado por la doctora Isabel Pujadas. Es docente en asignaturas de planeación urbana en grado de maestría. Sus líneas de investigación se centran en el estudio de la segregación urbana y las pautas de localización, concentración residencial de grupos sociales y movilidad urbana.

Jordi Bayona-i-Carrasco es licenciado en Geografía por la Universidad de Barcelona y doctor en Demografía por la Universidad Autónoma de Barcelona, con una tesis sobre los factores sociodemográficos que inciden en la distribución espacial de la población inmigrante en Barcelona. Es investigador del Centro de Estudios Demográficos y profesor asociado en el Departamento de Geografía de la Universidad de Barcelona. Sus líneas de investigación se centran en el estudio de la inmigración internacional y el análisis demográfico de la población de nacionalidad extranjera, en las pautas de segregación y concentración residencial de estas poblaciones a escala inframunicipal, y en las dinámicas migratorias internas y de movilidad residencial de la población. Puede consultarse su perfil en la siguiente dirección: http:// ced.uab.es/directori/jordi-bayona-carrasco/

Fernando Gil-Alonso es licenciado en Geografía e Historia por la Universidad de Barcelona, tiene un posgrado en Métodos y Técnicas para el Estudio de la Población por el Centro de Estudios Demográficos y es doctor en Geografía por la Universidad Autónoma de Barcelona. Es profesor agregado en el Departamento de Geografía de la Universidad de Barcelona y miembro del grupo de investigación consolidado Territorio, Población y Ciudadanía, coordinado por la doctora Isabel Pujadas, con quien codirige el Proyecto I+D 
"Desigualdad social, polarización territorial y formación de espacios vulnerables en las grandes áreas metropolitanas españolas", financiado por el Ministerio de Economía, Industria y Competitividad del Gobierno de España y por la Unión Europea. Fue investigador en la Unidad de Análisis Social y Demográfico de la Comisión Europea, en Bruselas (1998-2004), así como investigador del Centro de Estudios Demográficos y profesor asociado de la Universidad Autónoma de Barcelona. Es docente a nivel licenciatura y posgrado, y ha impartido seminarios sobre migraciones, fecundidad y mortalidad en instituciones nacionales y extranjeras. Es autor o coautor de más de un centenar de publicaciones, entre ellas unos cuarenta artículos en revistas académicas con índice de impacto nacional o internacional.

Fecha de recepción: 10 de octubre de 2016. Fecha de aceptación: 14 de marzo de 2017. 
